\title{
Eine Sprach-Mauer in den Köpfen? Über aktuelle Spracheinstellungen in Ost und West
}

\begin{abstract}
Es gibt zwar schon seit dem Mauerfall einen populären Diskurs über die Verständigungsschwierigkeiten zwischen Ost- und Westdeutschen und über die sprachlichen Unterschiede auf beiden Seiten. Über die Meinungen und Einstellungen zu sprachlichen Fragen ist aber so gut wie nichts bekannt. In diesem Beitrag wird untersucht, wie (bzw. wie verschieden) die Deutschen in Ost und West über das Deutsche, über andere Sprachen, über Sprachgebrauch und Sprachpolitik denken. Dabei zeigt sich, dass statistisch gesehen die Gemeinsamkeiten deutlich größer sind als die Unterschiede. Materielle Grundlage für die Untersuchung ist eine repräsentative Meinungsumfrage, die die Forschungsgruppe Wahlen im Herbst 2008 für das Institut für Deutsche Sprache und die Universität Mannheim durchgeführt hat.

The discourse about communication problems between East and West Germans and about linguistic differences between German in East and West has been popular since the fall of the Berlin Wall. But nearly nothing is known about opinions and attitudes regarding linguistic questions. This paper examines how (and how differently) Germans in East and West think about German and other languages, about language use and language politics. Our results indicate that, statistically, both East and West Germans have a lot more in common than there are differences. The data used for this study is drawn from a representative public opinion poll conducted by the Forschungsgruppe Wahlen (research group on elections) for the Institut für Deutsche Sprache and Mannheim University in autumn 2008.
\end{abstract}

\section{Die Mauer in den Köpfen}

Vierzig Jahre staatlicher Teilung, vierzig Jahre Zugehörigkeit zu verschiedenen politischen Blöcken, vierzig Jahre ideologische Segregation müssen Spuren hinterlassen haben. Achtundzwanzig Jahre Mauer müssen auch nach zwanzig Jahren noch zu spüren sein. Das ist das Gedankenkonstrukt, das der so eingängigen wie schrägen Metapher von der „Mauer in den Köpfen“ zugrunde liegt (und die Metapher wird desto schräger, je näher man hinsieht). Gemeint sind Schwierigkeiten im gegenseitigen Verstehen, die zum einen sehr grundsätzlich mit den unterschiedlichen Prägungen der Menschen in den beiden deutschen Staaten zu tun hatten, zum andern aber auch mit den Unterschieden im Beteiligtsein am Gestaltungsprozess der Vereinigung (und der unterschiedlichen Wahrnehmung dieser Unterschiede). Sucht man im Internet über Google nach dem Syntagma „Mauer in den Köpfen“, erhält man rund 140.000 Einträge (September 2009); offenbar ist die Formel gut verankert. Im Archiv der geschriebenen Sprache des Instituts für Deutsche Sprache führt die Suche über COSMAS zur - immer noch vergleichsweise hohen - Zahl von 458 Treffern aus dem Zeitraum von 1988 bis $2008 .{ }^{1}$ Das Reden von der Unterschiedlichkeit derjenigen, die schon immer Bundesbürger waren, und derjenigen, die es mit dem Ende der DDR wurden, hat nach wie vor Konjunktur; ein Topos in diesem Diskurs ist das Betonen der Differenz: „Sehr viele - nicht alle - Untersuchungen stimmen im Ergebnis überein: Ost- und Westdeutsche empfinden einander als sehr unterschiedlich, als fremd; sie sind

1 Der früheste Beleg stammt aus der Berliner tageszeitung vom 16.8.1988, also gut fünfzehn Monate vor der Grenzöffnung. 
voller Vorbehalte gegeneinander.“ (Hellmann 1998, S. 52) Dabei ist die Wahrnehmung von Unterschiedlichkeiten und Gemeinsamkeiten immer auch eine Frage des Maßstabs. Was aus mittlerer Distanz wie eine unüberbrückbare Verschiedenheit aussieht, mag aus größerem Abstand unter den großen Gemeinsamkeiten verdeckt werden und verschwinden, während sich aus der Nähe herausstellt, dass die Dinge noch viel kleinteiliger geordnet sind und sich entlang anderer Grenzen sortieren als bislang angenommen.

Dass es auf den verschiedensten Ebenen Unterschiede zwischen dem westlichen und dem östlichen Teil Deutschlands gibt, Unterschiede im Erleben, in den Biographien, in den Einstellungen, ist zunächst einmal eine triviale Feststellung. Hellmann betont zurecht: „Es gibt unterschiedliche Lebenserfahrungen in Ost und West, es gibt unterschiedliche Sozialisationen. Und dazu gehört selbstverständlich und nicht zuletzt der jeweils vertraute Sprachgebrauch.“ (Hellmann 2004, S. 19) Und prinzipiell steht zu erwarten, dass diese Unterschiede in der Sozialisation, die Unterschiede im gemeinsamen Erinnerungshorizont, in der kollektiven Perspektive auf die Welt von anderer Art sind als die regionalen Unterschiede, die man, bei der Wahl des entsprechenden Maßstabs, überall - auch innerhalb des Westens, auch innerhalb des Ostens - findet. Die Frage ist dann aber, von welcher Art diese Unterschiede sind, wie tief sie reichen, und ob sie überhaupt ein Problem darstellen müssen. Die Frage ist, ob die Kategorie der Ost-West-Unterschiede eine relevante Kategorie ist.

Von den tatsächlichen wie von den vermeintlichen sprachlichen Differenzen zwischen Ost und West war hier bereits ausführlich die Rede. ${ }^{2}$ In diesem Beitrag soll es darum gehen, wie die Deutschen in Ost und West auf die Sprache blicken, die sie teilen und die sie verbindet. Nicht der Sprachgebrauch, sondern die Einstellungen zur Sprache stehen hier im Vordergrund, die Meinungen und Haltungen, die die Sprachteilhaber zum Deutschen haben, auch zu anderen Sprachen, zu Fragen von Sprachpflege und Sprachpolitik, und auch welche Stereotype über sprachliche Formen transportiert werden. Die Unterschiede zwischen Ost und West, so wird sich zeigen, sind in vielen Bereichen weitaus weniger groß, als man vielleicht annehmen möchte; und sie sind dort, wo sie nachweisbar sind, oft gut zu plausibilisieren.

Materielle Grundlage der hier vorgestellten Überlegungen sind die im Mannheimer Forschungsprojekt „Erkundung und Analyse aktueller Spracheinstellungen in Deutschland“ erhobenen Daten. Bei diesem von der Volkswagen-Stiftung geförderten Projekt handelt es sich um eine interdisziplinär konzipierte Unternehmung des Instituts für Deutsche Sprache und des Lehrstuhls für Sozialpsychologie der Universität Mannheim. Zentraler Teil des Projekts ist eine bundesweite Repräsentativerhebung, die im Oktober 2008 im Auftrag der Projektpartner als Telefonumfrage von der Forschungsgruppe Wahlen durchgeführt wurde; erste Ergebnisse dieser Erhebung sind in Eichinger et al. (2009) sowie in Gärtig/ Rothe (2009) dargestellt. Im Zuge dieser Umfrage wurden rund 2000 zufällig ausgewählte Personen in über 60 Fragen zu ihren Einstellungen und Meinungen zum Deutschen und zu anderen Sprachen befragt; im einzelnen ging es dabei um Einstellungen zum Deutschen, um Dialekte und deren Bewertung, andere Sprachen in Deutschland, Sprachveränderungen, Sprachgebrauch und Sprachpflege, Sprachenvielfalt in der EU und Fremdsprachenbeherrschung. Die Ergebnisse der Umfrage sind repräsentativ, da die Gesamtstichprobe mit einem entsprechenden Schlüssel nach Geschlecht, Alter, Bildungsabschluss und

2 Nur exemplarisch: Stevenson (2002), Kreutz (2002), Bauer (1993). 
Wohnort gewichtet wurde, d.h. die Angaben der Befragten können auf die gesamte Wohnbevölkerung Deutschlands übertragen werden. Die sehr umfangreich angelegte Erhebung ermöglicht komplexe Auswertungen, so können etwa bestimmte Teilgruppen der Stichprobe untersucht und miteinander verglichen werden. Beispielsweise hinsichtlich ihres Wohnorts oder ihrer Herkunft oder auch hinsichtlich ihres Dialekts.

Für diesen Beitrag wurden die Befragten in zwei Gruppen, eine West-Gruppe und eine Ost-Gruppe, eingeteilt. Die West-Gruppebilden dieBefragten aus der alten Bundesrepublik, ${ }^{3}$ die Ost-Gruppe diejenigen aus der ehemaligen DDR. ${ }^{4}$ Die Analysen wurden zunächst sowohl für das Kriterium Wohnort als auch für das Kriterium Herkunft durchgeführt. Da für die Genese von Einstellungen jedoch nicht so sehr der aktuelle Wohnort eine Rolle spielt, sondern vor allem die Herkunft, also wo die Befragten vorwiegend aufgewachsen sind, maßgeblich ist, werden im Folgenden nur die Daten für die Herkunft der Befragten dargestellt.

Auf der Suche nach Ost-West-Unterschieden im Bereich der Spracheinstellungen wird man möglicherweise schon an der Oberfläche fündig. Die Frage nach den sprachlichen Unterschieden zwischen Ostdeutschen und Westdeutschen wird nicht erst seit dem realen Aufeinandertreffen der verschiedenen Sprachwirklichkeiten in größerem Maßstab seit der Grenzöffnung diskutiert, sondern hat eine Diskurstradition, die so alt ist wie die deutsche Teilung selber. ${ }^{5}$ Der erste Themenblock widmet sich daher der Frage der Wahrnehmung der sprachlichen Unterschiede zwischen Ost und West auf der einen und zwischen Nord und Süd auf der anderen Seite (Kapitel 2). Die allgemeinen Meinungen zur deutschen Sprache, auch die affektiven Haltungen, werden in Kapitel 3 dargestellt. Die verschiedenen Vorstellungen zu Sprachgebrauch, zur Frage der allgemeinen Sprachsorgfalt, der Wahrnehmung von Veränderungen in der Sprache und zu daraus unter Umständen ableitbaren sprachpolitischen Folgerungen sind Gegenstand von Kapitel 4. Der Blick aufs Eigene wird kontrastiert durch die verschiedenen Perspektiven, die man auf fremde Sprachen haben kann, angefangen vom Kontakt mit Zuwanderern bis zur Frage, welche Schulfremdsprachen man sich wünscht; derlei kommt in Kapitel 5 zur Sprache. In Kapitel 6 schließlich wird ein Blick auf die regionalen Varietäten geworfen; exemplarisch werden hier die verschiedenen Positionen zu Bairisch und Sächsisch (bzw. zu Bayern und Sachsen) behandelt. Der Beitrag schließt mit einer kurzen Zusammenfassung (Kapitel 7).

\section{Sprachliche Unterschiede zwischen Ost und West sowie zwischen Nord und Süd}

Sprache ist ein außerordentlich starker Identitäts-Marker. Über den gemeinsamen Sprachgebrauch bzw. umgekehrt über die Abgrenzung vom Sprachgebrauch der Anderen konstituieren und stabilisieren sich soziale Gruppen. Das funktioniert in großem Maßstab; das Konzept des Nationalstaats ist, zumindest in Mitteleuropa, eng mit einem Konzept einer Nationalkultur und einer Nationalsprachlichkeit verknüpft; im Alltagswissen vieler Sprecher sind Staatsgrenzen und Sprachgrenzen weitgehend deckungsgleich (in Belgien spricht man Belgisch). Und es funktioniert im kleinen Maßstab innerhalb einer Sprachge-

Schleswig-Holstein, Hamburg, Niedersachsen, Bremen, Nordrhein-Westfalen, Hessen, Rheinland-Pfalz, Saarland, Baden-Württemberg, Bayern sowie Berlin (West).

4 Mecklenburg-Vorpommern, Brandenburg, Sachsen-Anhalt, Thüringen, Sachsen sowie Berlin (Ost).

5 Zur Forschungsgeschichte bis zum Mauerfall vgl. Hellmann (in diesem Band). 
meinschaft, wo ein bestimmter Sprachgebrauch zuverlässig Gruppenzugehörigkeit signalisiert (wobei natürlich ein Sprecher je nach Situation und gewähltem Maßstab unterschiedlichen Gruppen angehören kann).

Die Behauptung, dass in einem so weiten Sinne die alte Bundesrepublik und die DDR unbeschadet ihrer prinzipiellen Zugehörigkeit zum gemeinsamen deutschen Sprachgebiet - zwei sprachlich distinkte Räume bilden, gehört zu den Konstanten des Ost-West-Diskurses nicht erst seit der Wiedervereinigung. Es scheint bei linguistischen Laien stabile Konzepte über die sprachlichen Unterschiede zwischen dem ehemaligen Westen und dem ehemaligen Osten zu geben. Fokussiert werden in diesem Zusammenhang in aller Regel Gebrauchsunterschiede im lexikalischen Bereich, wobei entweder auf eine verhältnismäBig geringe Zahl von tatsächlich nicht sehr frequenten Einzellexemen, die gleichwohl Schibboleth-Charakter erhalten haben, abgehoben wird (Broiler, Plaste, Datsche), oder aber der politisch-administrative Wortschatz im Vordergrund steht, dessen Differenzcharakter nicht überraschen kann, aber auch nichts Systematisches zu bedeuten braucht. ${ }^{6}$

Fragt man die Sprecher global nach ihrer Einschätzung der sprachlichen Unterschiede zwischen Ost- und Westdeutschen, dann ist dieser Differenzdiskurs etwas zu relativieren. Wenn man außerdem zugleich eine Komplementärfrage stellt, nämlich die nach der Einschätzung der sprachlichen Unterschiede zwischen Nord- und Süddeutschen, ergibt sich ein durchaus differenziertes Bild (Abbildung 1).

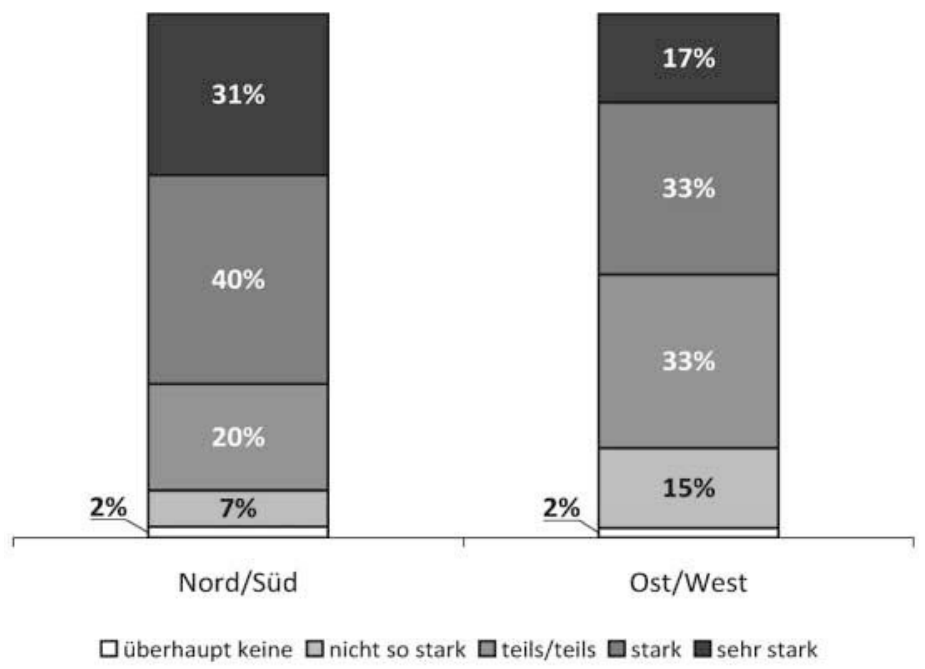

Abbildung 1: Sprachliche Unterschiede zwischen Nord und Süd sowie zwischen Ost und West

Fragen: Wie stark sind Ihrer Meinung nach die sprachlichen Unterschiede zwischen Nord- und Süddeutschen? (sehr stark, stark, teils/teils, nicht so stark, gibt es überhaupt keine, weiß nicht/keine Angabe) und Und wie stark sind Ihrer Meinung nach die sprachlichen Unterschiede zwischen den Ost- und Westdeutschen? (sehr stark, stark, teils/teils, nicht so stark, gibt es überhaupt keine, weiß nicht/keine Angabe)

6 Vgl. hierzu die Beiträge von Wolf und Steffens (beide in diesem Band). 
Das Ergebnis ist ziemlich markant. Wie Abbildung 1 zeigt, werden von der Gesamtgruppe der Befragten die sprachlichen Unterschiede zwischen Nord- und Süddeutschen als erheblich größer eingeschätzt (70,7 Prozent antworten ,stark“ oder ,,sehr stark“) als diejenigen zwischen Ost- und Westdeutschen (49,8 Prozent antworten ,stark“ oder „sehr stark“). Von einer sprachlichen Spaltung im Bewusstsein der Sprecher kann also offenkundig keine Rede sein.

Streng genommen werden hier natürlich verschiedene Dinge abgefragt. Das Kategorienpaar Ost-West in der Fragstellung evoziert den angesprochenen Ost-West-Diskurs und bewirkt eine politische Kontextualisierung. In diesem Rahmen bezeichnen die Begriffe Ost und West eindeutig keine geographischen Räume, sondern (ehemalige) politische Entitäten, nämlich die DDR und die alte Bundesrepublik, die als Bezugsgrößen im Bewusstsein der meisten Sprecher noch immer eine mentale Realität haben. In so einem Kategorisierungsmuster ist dann mit dem Westen nicht nur das Rheinland gemeint, sondern, ungeachtet der sprachgeographischen Unterschiede, auch Mannheim, Marburg und Freiburg, und nur in so einem Modell kann etwa die Hansestadt Wismar zum Osten, das geographisch viel weiter östlich gelegene Regensburg hingegen zum Westen gehören. Thematisiert man mit diesen groben Kategorien die Frage der sprachlichen Unterschiede, wird man als Orientierungsgrößen in aller Regel nicht verschiedene Dialekträume, sondern relativ standardnahe Sprechformen, die mit einzelnen Spezifika, die an die jeweiligen Kommunikationsräume der DDR und der alten Bundesrepublik anschließen, angereichert sind, erhalten, wobei die „Prestige-Varietät Westdeutsch“ (Holly/Habscheid 1997, S. 97) aus westlicher Sicht nur den unveränderten Default-Fall darstellt. Die innerdeutsche Grenze wird so zur innerdeutschen Sprachgrenze hypostasiert.

Die Nord-Süd-Kategorisierung hingegen ist primär eine geographische und nicht eine politische, auch wenn sie möglicherweise auch durch die Nachwirkungen einer alten politischen Konstellation grundiert wird (Preußen versus Habsburg). Vor allem aber hat diese Kategorisierung bereits innerhalb der alten Bundesrepublik funktioniert; Protagonisten sind ein relativ standardnahes und daher vielfach als schriftsprachorientiert wahrgenommenes Norddeutsch auf der einen Seite und verschiedene Formen von süddeutschen Regionalstandards, die eine dialektale Basierung erkennen lassen (prototypisch in Form eines bayerischen oder schwäbischen Akzents), auf der anderen Seite eine klare Grenze zwischen beiden gibt es nicht, sondern allenfalls ein breites Übergangsgebiet ohne eindeutiges Diesseits und Jenseits. Anders als beim Ost-West-Vergleich sind es hier auch nicht primär lexikalische Elemente, die als Träger der regionalen Markierung fungieren, sondern vor allem phonetisch-prosodische und morphologische Merkmale.

Umso bemerkenswerter ist es vor diesem Hintergrund, dass die Wahrnehmung der sprachlichen Unterschiede zwischen Nord und Süd im Westen und im Osten recht ähnlich - und eben ähnlich hoch - ausfällt (Abbildung 2). 


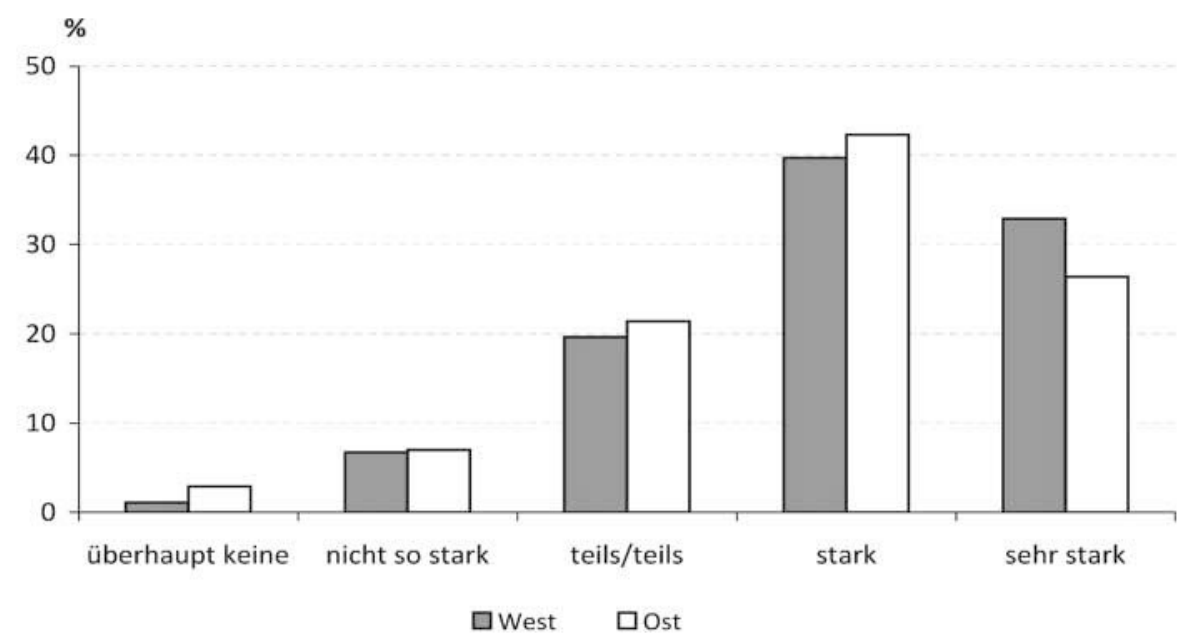

Abbildung 2: Sprachliche Unterschiede zwischen Nord und Süd, nach Herkunft (Fragen wie Abbildung 1)

Insgesamt werden die sprachlichen Nord-Süd-Unterschiede im Westen als etwas höher eingeschätzt als im Osten (die Antwort ,stark“ oder ,sehr stark“ geben im Westen 72,6 Prozent, im Osten 68,7 Prozent); vor allem ist die Gruppe derjenigen, die „sehr starke“ Unterschiede wahrnehmen, im Westen größer als im Osten (32,9 Prozent im Westen gegenüber 26,4 Prozent im Osten).

Erheblich größer sind jedoch die Differenzen bei der Frage nach den sprachlichen OstWest-Unterschieden. Die Unterschiede zwischen Ost und West werden - allerdings auf einem insgesamt niedrigeren Niveau als die Nord-Süd-Unterschiede - von den Befragten im Westen als stärker wahrgenommen als von den Befragten im Osten. Im Osten antwortet die größte Gruppe (41,2 Prozent) mit ,teils/teils“; die Antwort ,stark“ oder ,sehr stark“ geben im Westen 54,9 Prozent, im Osten dagegen nur 35,7 Prozent (Abbildung 3).

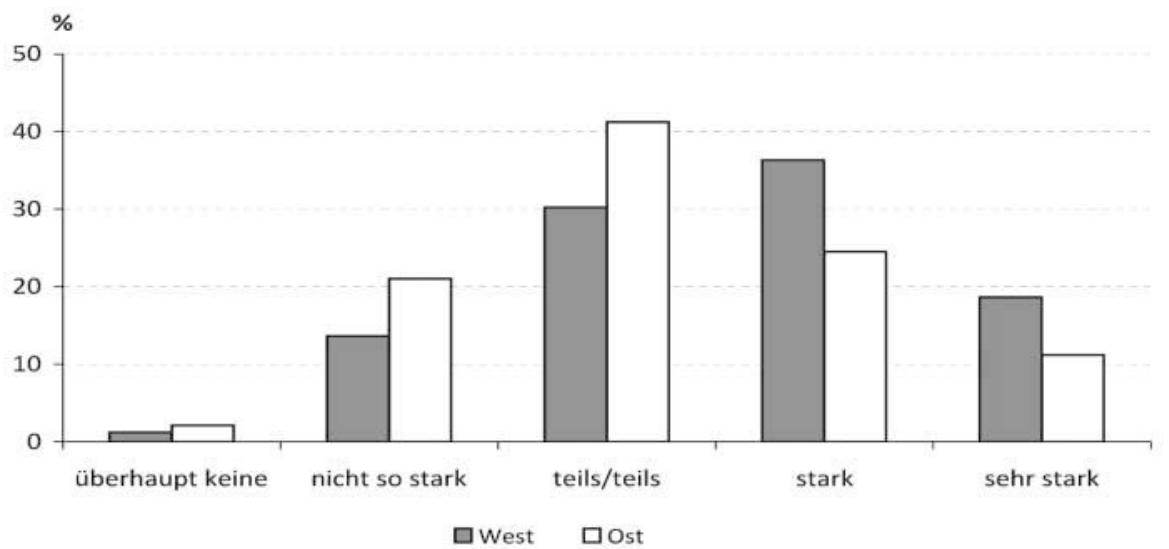

Abbildung 3: Sprachliche Unterschiede zwischen Ost und West, nach Herkunft (Fragen wie Abbildung 1) 
Diese unterschiedlichen Verhältnisse lassen sich auch über einen Vergleich der Mittelwerte der Antworten auf die jeweilige Frage visualisieren (Abbildung 4). Hier ist auf der y-Achse die Ausprägung des jeweiligen Merkmals abgebildet, der Wert 1 stellt dabei die niedrigste Ausprägung dar (in diesem Fall die Antwort ,gibt es überhaupt keine“), der Wert 3 die Antwortkategorie ,teils/teils“ und der Wert 5 die höchste Ausprägung (hier die Antwort ,sehr stark“). Man sieht, dass die Mittelwerte sowohl bei den Nord-Süd-Unterschieden (linkes Balkenpaar) als auch bei den Ost-West-Unterschieden (rechtes Balkenpaar) im Westen (jeweils der linke, dunkle Balken) insgesamt höher sind als im Osten (jeweils der rechte, helle Balken), d.h. die Antworten im Westen verteilen sich bei beiden Fragen stärker auf die Antwortkategorien ,sehr stark“ und ,stark“, als dies im Osten der Fall ist. Der Asterisk kennzeichnet hierbei einen statistisch signifikanten Unterschied. ${ }^{7}$

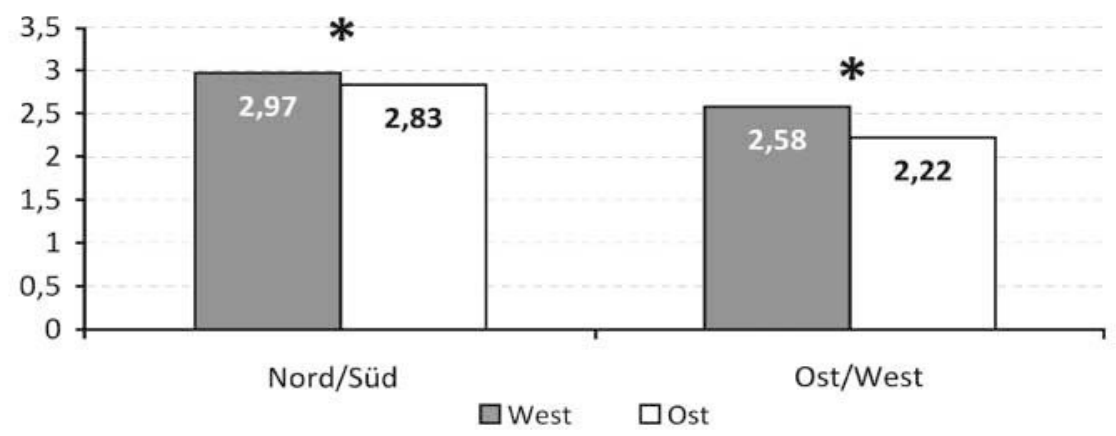

Abbildung 4: Sprachliche Unterschiede zwischen Nord und Süd sowie zwischen Ost und West - Vergleich der Mittelwerte (nach Fragestellung) (Fragen wie Abbildung 1)

Dass, wie bereits in Abbildung $1 \mathrm{zu}$ sehen war, zumindest in sprachlicher Hinsicht in der Wahrnehmung der Sprecher tatsächlich nicht die Ost-West-Gegensätze, sondern die NordSüd-Unterschiede dominieren, veranschaulicht auch der Vergleich der Mittelwerte in Abbildung 5. Hier beziehen sich die Doppelbalken nicht auf die Fragestellung, sondern auf die Teilgruppen der Befragten. Man erkennt unmittelbar, dass sowohl im Westen (linkes Balkenpaar) als auch im Osten (rechtes Balkenpaar) die Werte für die Nord-SüdUnterschiede deutlich über denjenigen der Ost-West-Unterschiede liegen. Offenbar dominiert die geographisch-dialektale Orientierung gegenüber derjenigen an den ehemaligen politischen Grenzen.

Die Likertskalen wurden wie allgemein üblich als Ordinaldaten behandelt, entsprechend wurde die Signifikanz mit t-Tests und ANOVA-Analysen ermittelt. Für die Nominaldaten wurden Chi-QuadratTests durchgeführt. 


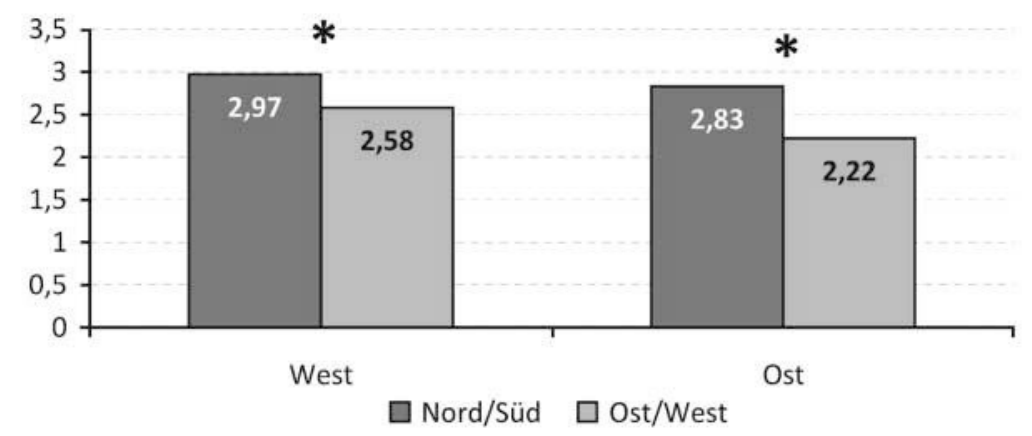

Abbildung 5: Sprachliche Unterschiede zwischen Nord und Süd sowie zwischen Ost und West - Vergleich der Mittelwerte (nach Herkunft) (Fragen wie Abbildung 1)

Inwieweit hier mit zunehmendem historischen Abstand von der Zeit der Zweistaatlichkeit deren Relevanz als Orientierungsgröße abnimmt, lässt sich nur auf der Grundlage der hier untersuchten Daten, die ja eine Momentaufnahme darstellen, nicht zuverlässig beurteilen. ${ }^{8}$ Intuitiv erschiene es als plausibel; die Frage der sprachlichen Ost-West-Differenzen wäre dann vor allem eine Generationenfrage, wie es auch Hellman nahelegt:

Junge Leute von heute aus Ost und West reagieren auf ost- bzw. westtypische Wörter und Wendungen aus der Zeit vor 1989 ganz ähnlich, unabhängig von ihrer Herkunft, ältere Leute aus Ost und West aber unterschiedlich, abhängig von ihrer Herkunft. (Hellmann 2004, S. 19) ${ }^{9}$

Aus diesen Beobachtungen ließe sich die Hypothese ableiten, dass die Frage nach den sprachlichen Unterschieden altersabhängig unterschiedlich beantwortet werden sollte. Unterteilt man die Befragten nach Altersgruppen und bildet die Antworten gestaffelt entsprechend den obigen Darstellungen ab, ergibt sich allerdings kein ganz klares Muster. Ein deutlicher Alterseffekt in der einen oder anderen Form (klar unterschiedliche oder auch klar nicht unterschiedliche Bewertungen je nach Frage, Herkunft, Alter) ist nicht

8 Das Institut für Deutsche Sprache hat 1997/98 schon einmal eine Repräsentativumfrage zu Meinungen und Einstellungen zur deutschen Sprache durchgeführt (Stickel/Volz 1999). Die Zahlen, die bei dieser früheren IDS-Umfrage erhoben wurden, sind für einen Vergleich mit der aktuellen Erhebung jedoch nur mit Einschränkung geeignet, weil die Fragen z.T. anders formuliert waren (vgl. Stickel/Volz 1999, S. 32-37). Damals (1997/98) antworteten auf die Frage nach sprachlichen Unterschieden zwischen den alten und den neuen Bundesländern (auf einer Dreierskala) 17,9 Prozent der Befragten aus dem Westen mit „sehr viele“; im Osten waren es nur 10,8 Prozent. Ein etwa gleich großer Anteil der Befragten in Ost und West gab an, dass es „einige“ Unterschiede gebe (40,5 Prozent aus dem Westen, 40,1 Prozent aus dem Osten). 41,7 Prozent der Befragten im Westen und 49,1 Prozent im Osten sahen ,keine bemerkenswerten" sprachlichen Unterschiede. Ähnlich wie heute (Abbildung 4) wurden also im Westen eher Unterschiede wahrgenommen als im Osten. - Auch die Beobachtung, dass Nord-Süd-Unterschiede stärker wahrgenommen werden als Ost-West-Unterschiede (Abbildung 5), lässt sich mit den Daten von vor zehn Jahren in Beziehung bringen. Damals beantworteten die Frage, ob ,die sprachlichen Unterschiede zwischen Ostdeutschen und Westdeutschen größer als die sprachlichen Unterschiede zwischen Norddeutschen und Süddeutschen" erschienen, 29,4 Prozent der Befragten aus dem Westen bzw. 23,4 Prozent aus dem Osten mit ,ja, größer“, 70,6 Prozent aus dem Westen bzw. 76,6 Prozent mit „,nein, nicht größer“ (wobei sich diese letzten Daten nur auf eine Teilstichprobe beziehen). Quantitative Veränderungen im einzelnen lassen sich aufgrund des unterschiedlichen Fragedesigns nicht nachweisen; die Grundverhältnisse waren aber offenbar vor zehn Jahren ähnlich.

9 Durchaus typisch für den sprachlichen Ost-West-Diskurs ist übrigens, wie oben angedeutet, auch hier wieder die Referenzgröße zur Differenzbestimmung der Wortschatz. 
feststellbar; die abbildbaren Unterschiede ergeben kein klares Muster, weshalb auch auf ihre Darstellung in einer eigenen Abbildung verzichtet werden kann. Das mag damit zusammenhängen, dass die Zahlen für die einzelnen Gruppen ab einem gewissen Differenzierungsgrad recht klein werden, bei einer erheblich größeren Datengrundlage ergäben sich vielleicht klarere Bilder. Möglicherweise liegt in dieser Frage jedoch auch tatsächlich kein Generationeneffekt vor.

\section{Meinungen zu Deutsch}

Die Frage nach den sprachlichen Unterschieden ist zunächst eine Frage nach Grenzwahrnehmungen. Sie fragt nach Selbst- und Fremdwahrnehmungen, und wo die sprachlichen Unterschiede zwischen Ost und West abgefragt werden, wird die vermutete Differenz der Befragtengruppen selbst zum Gegenstand. Was mit einer solchen Fragestellung erhoben wird, sind Einschätzungen der Befragten, ihre Urteile über die Welt. Das ist, wie das vorige Kapitel gezeigt hat, durchaus aufschlussreich. Es werden jedoch noch keine Einstellungen erfragt, keine Meinungen über diese Einschätzungen und keine Meinungen über die Welt. Nun wäre eine naheliegende Hypothese, dass Ost- und Westdeutsche zwar, wie gezeigt, in der Beurteilung der Welt nicht so weit auseinander liegen, dass sich aber, als Folge der jahrzehntelangen staatlichen Teilung, der Zugehörigkeit zu verschiedenen politischen Blöcken, als Folge je unterschiedlicher Sozialisation in unterschiedlichen Wertesystemen, in ihrer Bewertung durchaus Differenzen nachweisen lassen, die nicht auf Zufall beruhen. In diesem Kapitel sollen diejenigen Fragen der Erhebung, die sich auf Meinungen über das Deutsche in einem sehr allgemeinen Sinne bezogen, vorgestellt werden, jeweils bezogen auf die Herkunft der Befragten nach Ost und West: zunächst allgemeine Spracheinstellungen (Abschnitt 3.1), dann die Zuschreibung bestimmter Eigenschaften (Abschnitt 3.2), anschließend Gefühle gegenüber der deutschen Sprache (Abschnitt 3.3) und schließlich stereotype Ansichten über Personen (Abschnitt 3.4). Dabei zeigt sich, dass die Unterschiede zwischen Ost und West in diesem Themenbereich insgesamt relativ gering ausfallen.

\subsection{Allgemeine Spracheinstellungen}

Das deutet sich bereits bei der allgemeinen Frage zum generellen Interesse an sprachlichen Fragen an (Abbildung 6, obere Hälfte). Insgesamt ist das Sprachinteresse recht ausgeprägt; mehr als ein Drittel der Befragten - und damit erheblich mehr als bei der IDSUmfrage von 1997/98 ${ }^{10}$ - geben an, dass sie sich ,stark“ oder ,sehr stark“ für sprachliche Fragen interessieren. Dabei liegen die Werte für die Ostdeutschen zwar geringfügig unter denen der Westdeutschen, der Unterschied wird jedoch statistisch nicht signifikant. ${ }^{11}$

Ähnlich verhält es sich bei der Frage nach dem Gefallen an der deutschen Sprache (Abbildung 6, untere Hälfte). Die Werte sind insgesamt hoch, vor allem gibt es praktisch keine ablehnenden Äußerungen (nur 1,2 Prozent der Befragten antworten mit ,schlecht“ oder

10 Die Antworten von 1997/98: „,sehr stark“ 3,6 Prozent, ,stark“ 9,2 Prozent, „,mittel“ 30,2 Prozent, ,,wenig“ 31,5 Prozent, ,überhaupt nicht“ 25,0 Prozent (Stickel/Volz 1999, S. 15-16).

11 Auch bei der IDS-Umfrage von 1997/98 vermeldeten die Befragten aus dem Osten - bei einem insgesamt niedrigeren Niveau - ein geringfügig niedrigeres allgemeines Sprachinteresse als diejenigen aus dem Westen, allerdings wurden die Angaben nicht auf statistische Signifikanz geprüft (vgl. Stickel/Volz 1999, S. 15-16 und zuletzt Stickel 2006). 
„sehr schlecht"); sie sind allerdings im Schnitt - und zwar signifikant - im Westen noch etwas höher als im Osten.

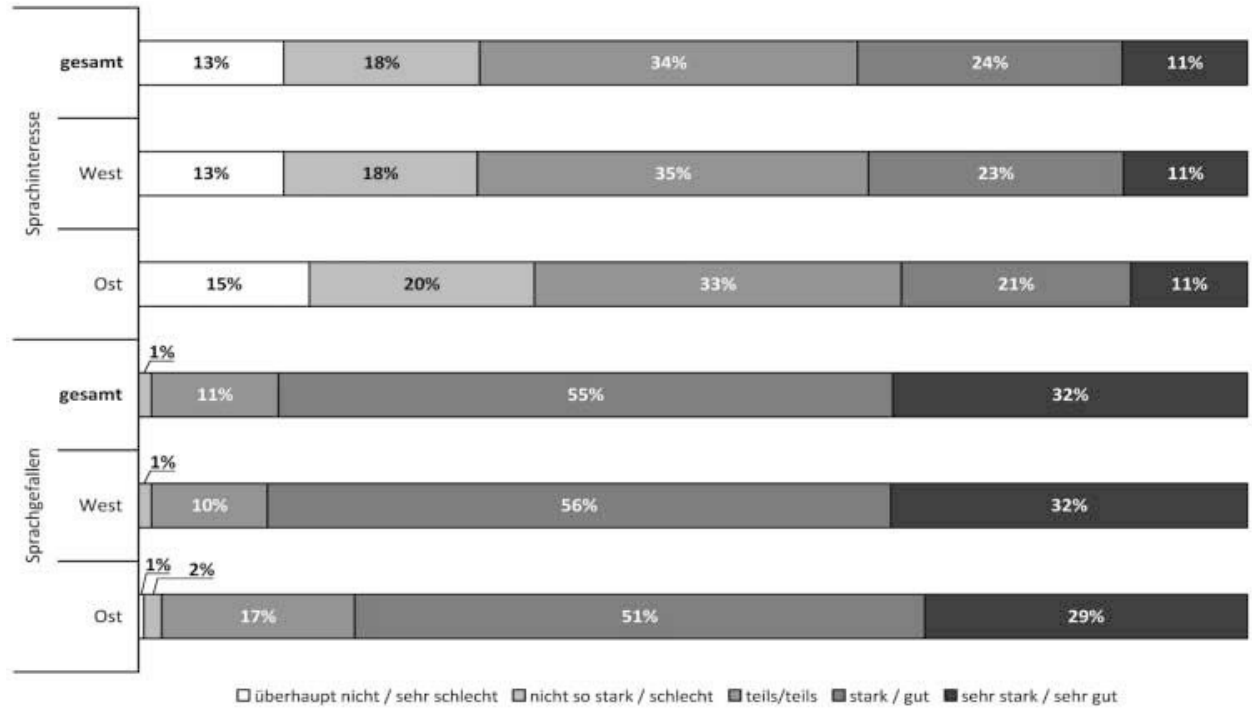

Abbildung 6: Sprachinteresse und Sprachgefallen (nach Herkunft)

Fragen: Wie stark interessieren Sie sich ganz allgemein für Fragen, die mit Sprache zu tun haben? (sehr stark, stark, teils/teils, nicht so stark, überhaupt nicht, weiß nicht/keine Angabe) und Wie gut gefällt Ihnen ganz allgemein die deutsche Sprache? (sehr gut, gut, teils/teils, schlecht, sehr schlecht, weiß nicht/keine Angabe)

Der Vergleich der Mittelwerte zu diesen beiden Fragen macht augenfällig, dass erstens die West-Ost-Differenzen nicht sehr groß sind und dass zweitens die Antworten zum Gefallen an der deutschen Sprache insgesamt sehr positiv ausfallen (Abbildung 7).

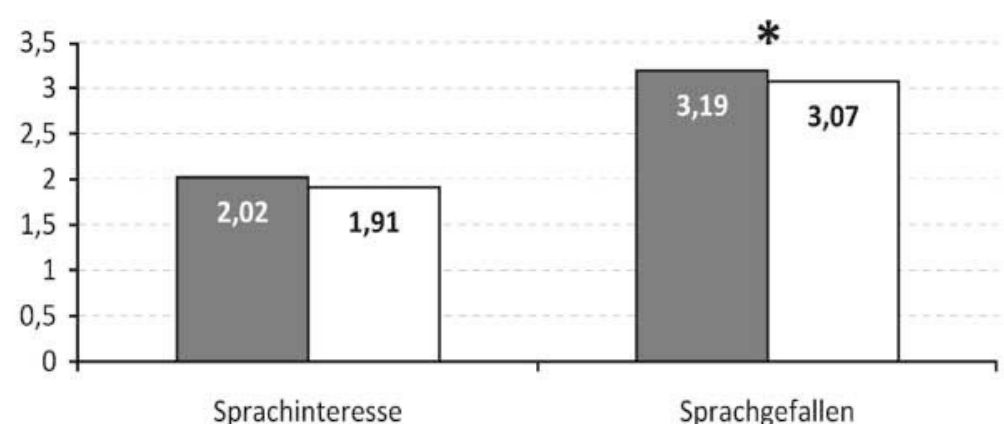

$\square$ West $\square$ ost

Abbildung 7: Sprachinteresse und Sprachgefallen (nach Herkunft) - Vergleich der Mittelwerte (Fragen wie Abbildung 6) 
Ob jemand Interesse an der Sprache hat und an ihr Gefallen findet, hängt offenbar nicht in erster Linie davon $\mathrm{ab}$, ob der Betreffende aus den alten oder den neuen Bundesländern stammt. Tatsächlich spielen eine Reihe anderer Faktoren eine Rolle; so geben besonders diejenigen Personen an, dass ihnen die deutsche Sprache gefällt, die sich stärker mit Deutschland verbunden fühlen, die konservativer sind und die ihre eigene wirtschaftliche Lage positiv bewerten. Auch Alter sowie das allgemeine Interesse an sprachlichen Fragen sind begünstigende Faktoren - während etwa das Geschlecht oder auch der Bildungsabschluss keinen statistisch erkennbaren Einfluss haben (vgl. Eichinger et al. 2009, S. 7-9).

\subsection{Eigenschaftszuschreibungen}

Um die Einstellungen der Befragten gegenüber der deutschen Sprache zu ermitteln, wurde das von Osgood/Suci/Tannenbaum (1957) entwickelte Verfahren des semantischen Differentials eingesetzt. Dabei wird den Probanden eine Liste von (in diesem Fall fünfstufigen) bipolaren Skalen vorgelegt, deren Pole durch antonyme Adjektive bezeichnet sind. Erfasst wurden drei Faktoren über je zwei Items: der Faktor Wert, über die Items anziehend abstoßend und schön - hässlich (Abbildung 8), der Faktor Struktur über die Items logisch - unlogisch und einfach - schwierig (Abbildung 9), und der Faktor Klang, über die Items weich - hart und melodisch - unmelodisch (Abbildung 10). ${ }^{12}$ Danach bewertet die Mehrheit der Befragten die deutsche Sprache als ,anziehend“ (51,2 Prozent), ,schön“ (76,3 Prozent) und „logisch“ (63,8 Prozent), zugleich aber auch als „schwierig“ (57,2 Prozent). Die Eigenschaften „weich“ und „melodisch“ polarisieren hingegen deutlich weniger.

Auch bei diesem Fragenkomplex liegen die Antworten der Befragten in Ost- und Westdeutschland auffällig dicht beieinander.

12 Die Auswahl der Items erfolgte nach einer explorativen Faktorenanalyse auf der Grundlage von 62 semantischen Differentialen; es wurden für jeden Faktor die beiden Items ausgewählt, die am höchsten auf ihrem Faktor luden. 


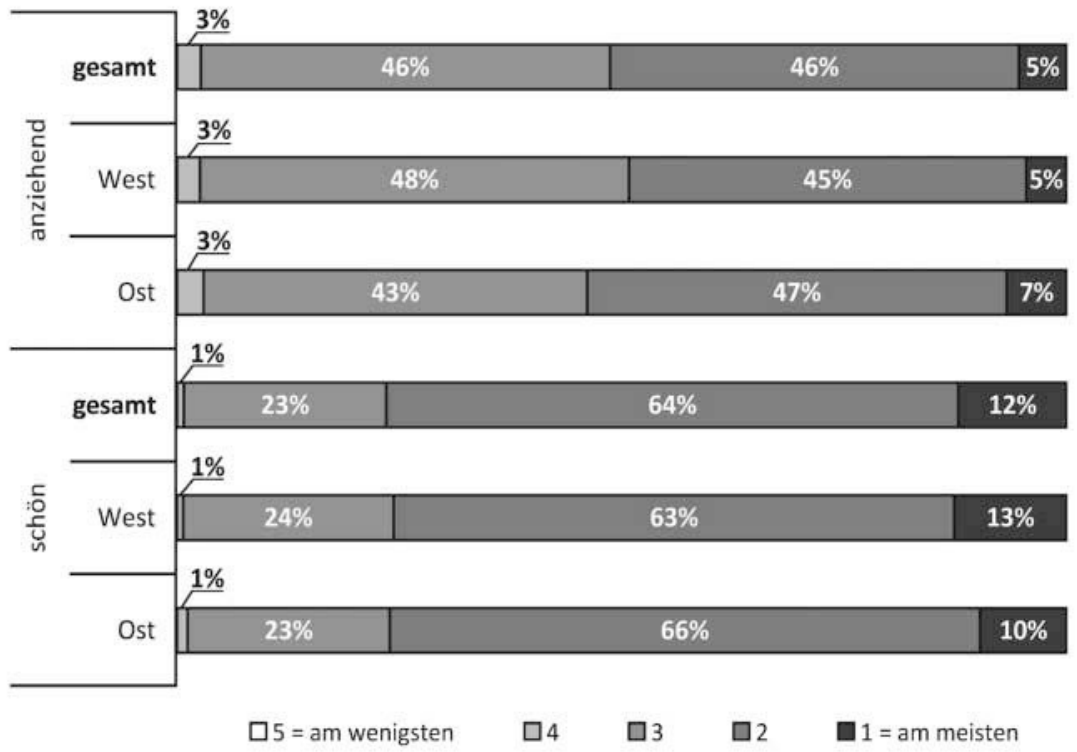

Abbildung 8: Eigenschaftszuschreibung: Wert (nach Herkunft)

Fragen: Wie ist Ihrer Meinung nach die deutsche Sprache? Ist die deutsche Sprache ... a) sehr anziehend, anziehend, teils/teils, abstoßend, sehr abstoßend, weiß nicht/keine Angabe? und b) sehr schön, schön, teils/ teils, hässlich, sehr hässlich, weiß nicht/keine Angabe?

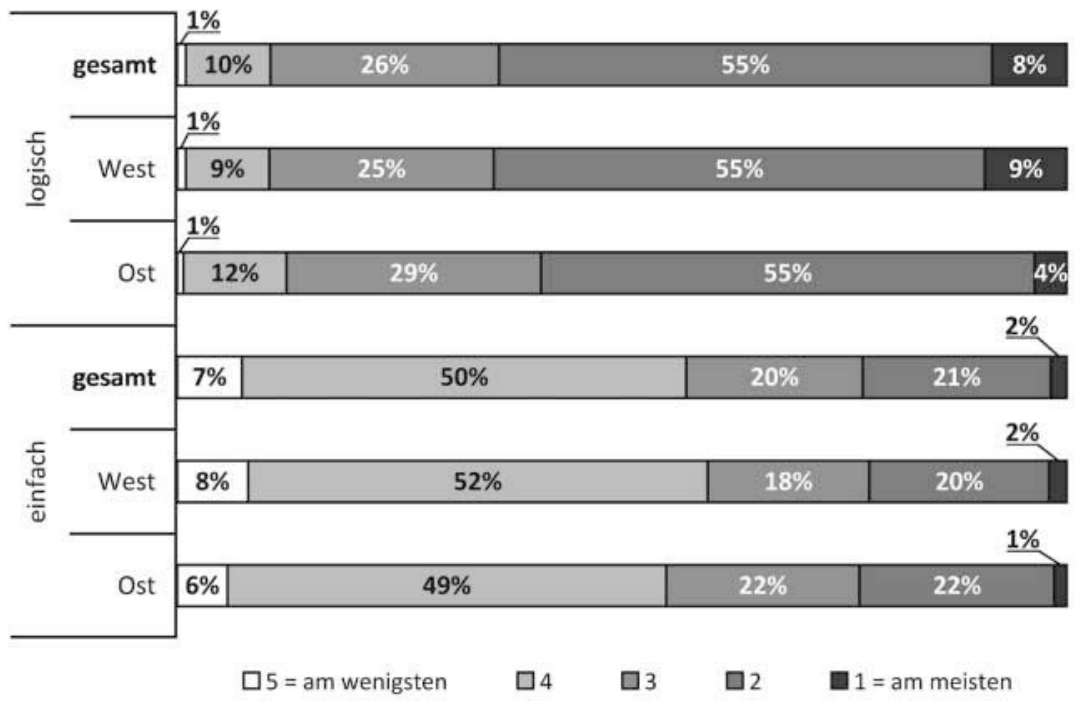

Abbildung 9: Eigenschaftszuschreibung: Struktur (nach Herkunft)

Fragen: Wie ist Ihrer Meinung nach die deutsche Sprache? Ist die deutsche Sprache ... a) sehr logisch, logisch, teils/teils, unlogisch, sehr unlogisch, weiß nicht/keine Angabe? und b) sehr einfach, einfach, teils/ teils, schwierig, sehr schwierig, weiß nicht/keine Angabe? 


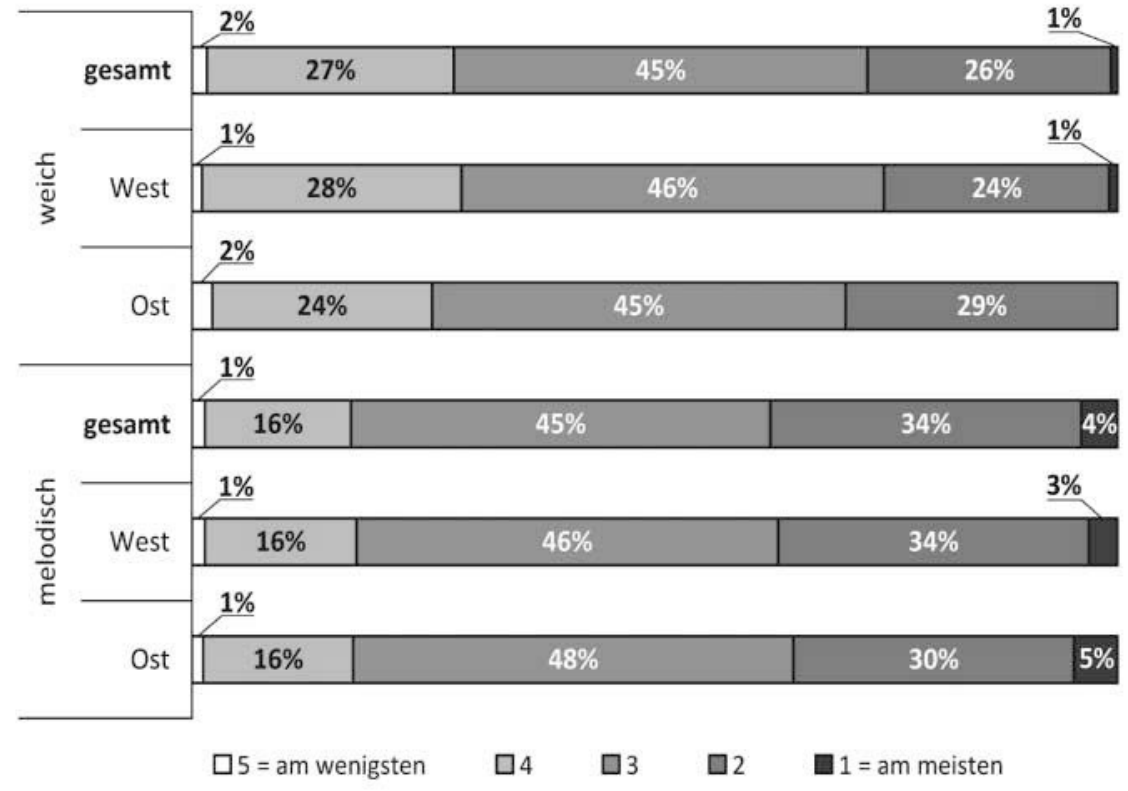

Abbildung 10: Eigenschaftszuschreibung: Klang (nach Herkunft)

Fragen: Wie ist Ihrer Meinung nach die deutsche Sprache? Ist die deutsche Sprache ... a) sehr weich, weich, teils/teils, hart, sehr hart, weiß nicht/keine Angabe? und b) sehr melodisch, melodisch, teils/teils, unmelodisch, sehr unmelodisch, weiß nicht/keine Angabe?

Auch der Vergleich der Mittelwerte zeigt, dass es in diesem Bereich keine markanten Unterschiede zwischen Ost und West gibt (Abbildung 11). Der Faktor Wert (,anziehend“ und ,schön“) wird einhellig hoch bewertet (ein Befund, der auch gut mit den in den Abbildungen 6 und 7 dargestellten Antworten auf die Frage nach dem Sprachgefallen korrespondiert). Beim Faktor Struktur erreicht das Merkmal „logisch“ hohe Mittelwerte, das Merkmal „einfach“ hingegen niedrige (bzw. umgekehrt das Merkmal „schwierig“ hohe) Mittelwerte - was durchaus kein Widerspruch zu sein braucht. Das Merkmal „logisch“ ist das einzige, bei dem ein Unterschied zwischen den ost- und westdeutschen Befragten statistisch signifikant wird; die Befragten im Westen bewerten die deutsche Sprache in etwas höherem Maße als logisch als die Befragten im Osten (Mittelwert 2,62 im Westen gegenüber 2,50 im Osten). Beim Faktor Klang wiederum (,,weich“ und „,melodisch“) liegen die Mittelwerte sehr dicht zusammen (beim Merkmal „melodisch“ sind sie sogar identisch). 


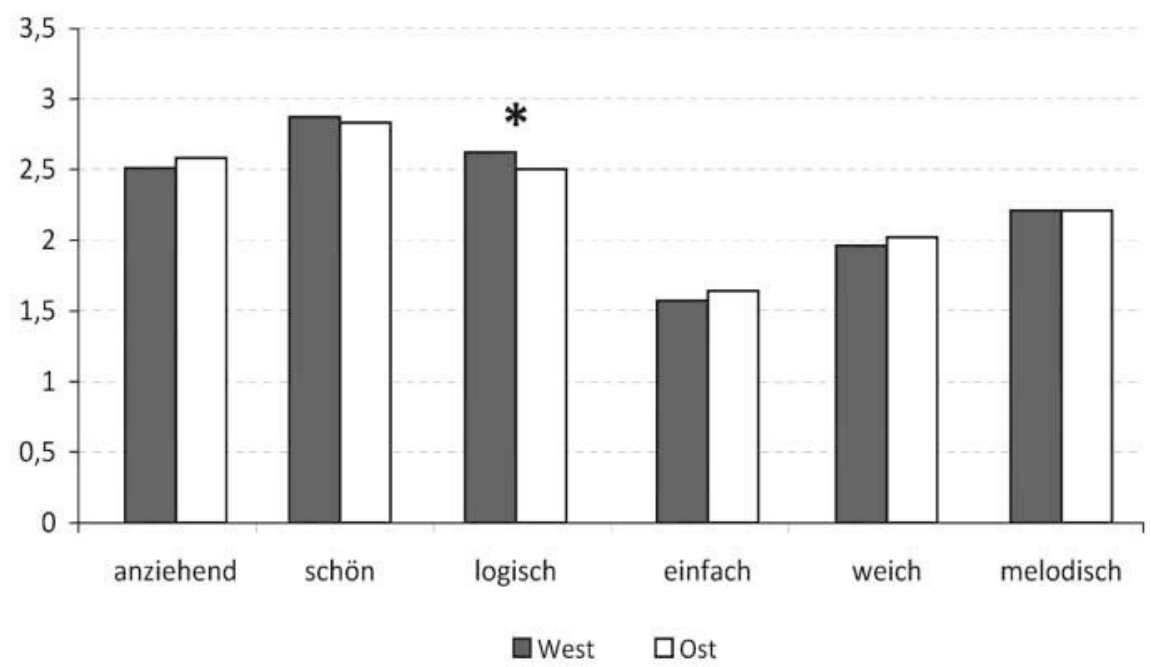

Abbildung 11: Eigenschaftszuschreibungen (nach Herkunft) - Vergleich der Mittelwerte (Fragen wie Abbildungen 8 bis 10 )

\subsection{Gefühle gegenüber der deutschen Sprache}

In einem weiteren Schritt wurden die Befragten gebeten anzugeben, wie stark sie bestimmte Emotionen gegenüber der deutschen Sprache empfänden. Abgefragt wurden zwei positive Emotionen (Stolz und Liebe; Abbildung 12) sowie zwei negative (Abneigung und Gleichgültigkeit; Abbildung 13). ${ }^{13}$

Tatsächlich findet sich bei den positiven Emotionen ein Unterschied zwischen den ostdeutschen und den westdeutschen Befragten, der zwar nicht sehr hoch ausfällt, aber doch statistisch signifikant wird. Die Befragten aus dem Osten geben öfter an, Stolz und Liebe für die deutsche Sprache zu empfinden, als die Befragten im Westen: 54,5 Prozent der Befragten im Westen gegenüber 63,0 Prozent im Osten geben an, ,stark“ oder ,sehr stark“ Stolz zu empfinden, 45,9 Prozent im Westen und 52,0 Prozent im Osten empfinden Liebe für die deutsche Sprache.

Hinsichtlich der Antworten auf die Fragen nach den negativen Emotionen (Abneigung bzw. Gleichgültigkeit) hingegen unterscheiden sich die Befragten in Ost und West nicht. Abneigung ,überhaupt nicht“ zu empfinden, geben im Westen 70,4 Prozent, im Osten 69,6 Prozent der Befragten an. Nicht ganz so hoch, aber immer noch deutlich sind die negativen Werte bei der Frage nach der Gleichgültigkeit, von der im Westen 51,8 Prozent und im Osten 48,6 Prozent der Befragten angeben, sie ,überhaupt nicht“ zu empfinden.

13 Die Auswahl erfolgte wie bei den semantischen Differentialen auf der Grundlage von Vortests, hier mit je acht positiven und negativen Emotionen (in Anlehnung an Shaver et al. 1987). 


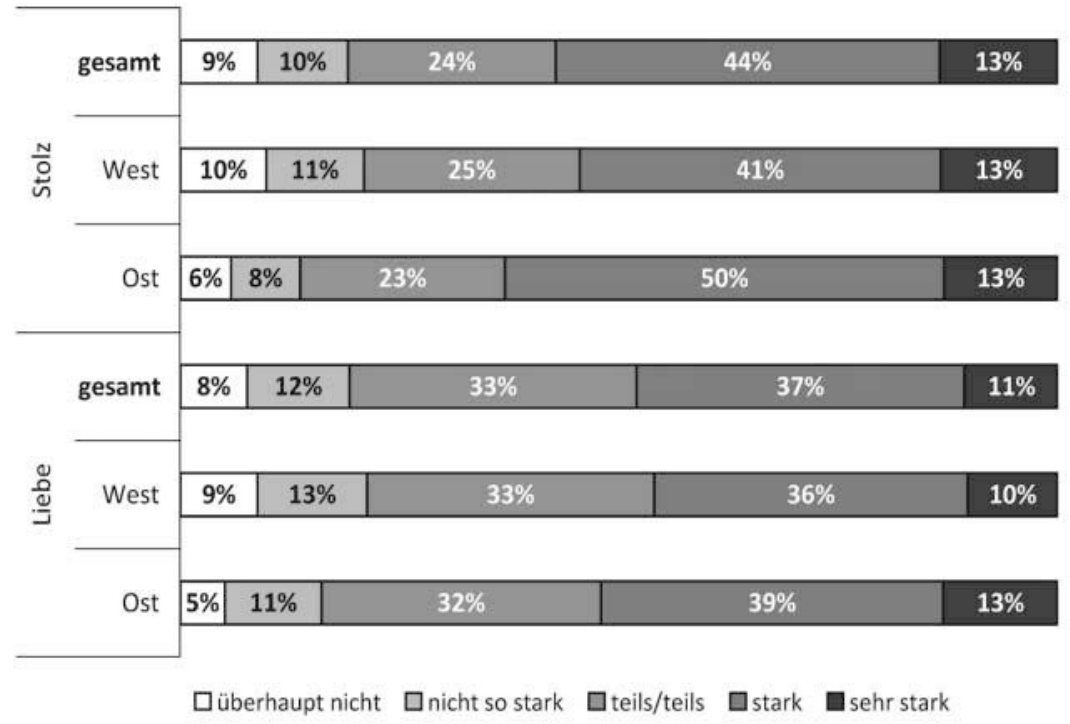

Abbildung 12: Stolz, Liebe (nach Herkunft)

Fragen: Wie stark empfinden Sie persönlich folgende Gefühle gegenüber der deutschen Sprache? Wie stark empfinden Sie ... a) Stolz? und b) Liebe? (Reihenfolge randomisiert), jeweils: sehr stark, stark, teils/teils, nicht so stark, überhaupt nicht, weiß nicht/keine Angabe

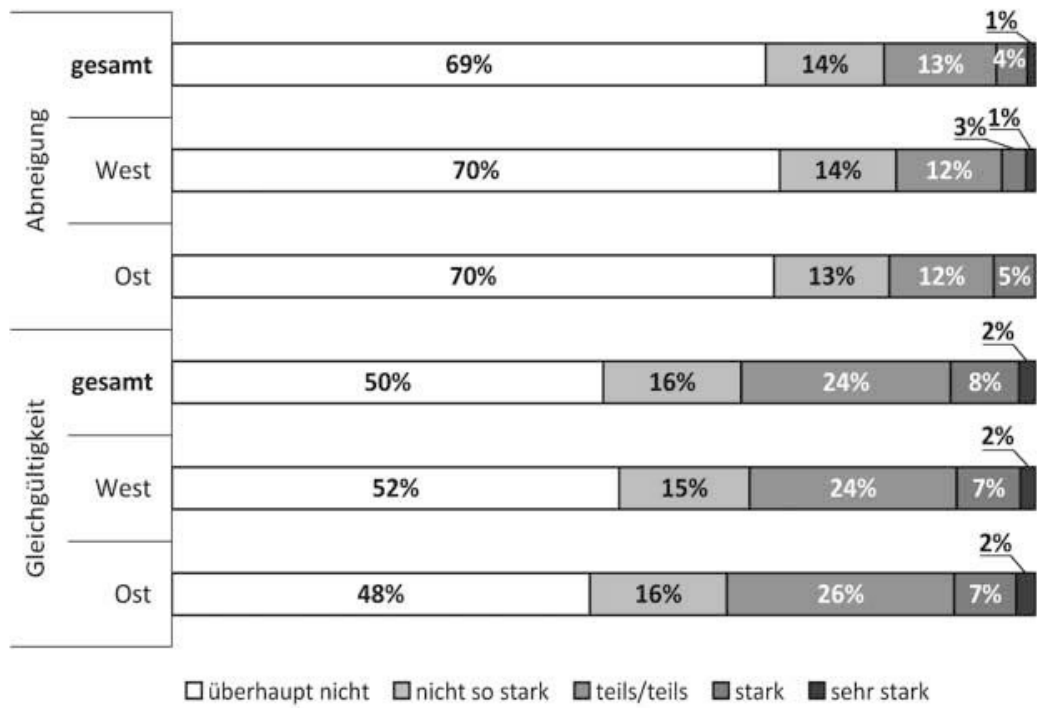

Abbildung 13: Abneigung, Gleichgültigkeit (nach Herkunft)

Fragen: Wie stark empfinden Sie persönlich folgende Gefühle gegenüber der deutschen Sprache? Wie stark empfinden Sie ... a) Abneigung? und b) Gleichgültigkeit? (Reihenfolge randomisiert), jeweils: sehr stark, stark, teils/teils, nicht so stark, überhaupt nicht, weiß nicht/keine Angabe 
Der Vergleich der Mittelwerte veranschaulicht diese Daten noch einmal (Abbildung 14). Zwei Dinge werden in dieser Darstellung deutlich. Erstens sind offenbar die Einstellungen, die die Deutschen gegenüber ihrer Sprache haben, im Grundsatz sehr positiv, wie die hohen Werte bei Stolz und Liebe sowie die sehr niedrigen Werte bei Abneigung (mit eindeutig negativer Konnotierung) und die niedrigen Werte bei Gleichgültigkeit (mit negativer bis unter Umständen neutraler Konnotierung) zeigen. ${ }^{14}$ Zweitens sieht man im Vergleich der alten und neuen Bundesländer, dass die negativen Emotionen in etwa in derselben (niedrigen) Größenordnung liegen, dass aber die Befragten im Osten signifikant häufiger angeben, Stolz und Liebe für die deutsche Sprache zu empfinden - ein Befund, der allerdings ohne weitere Kontextualisierung schwer zu interpretieren ist. ${ }^{15}$

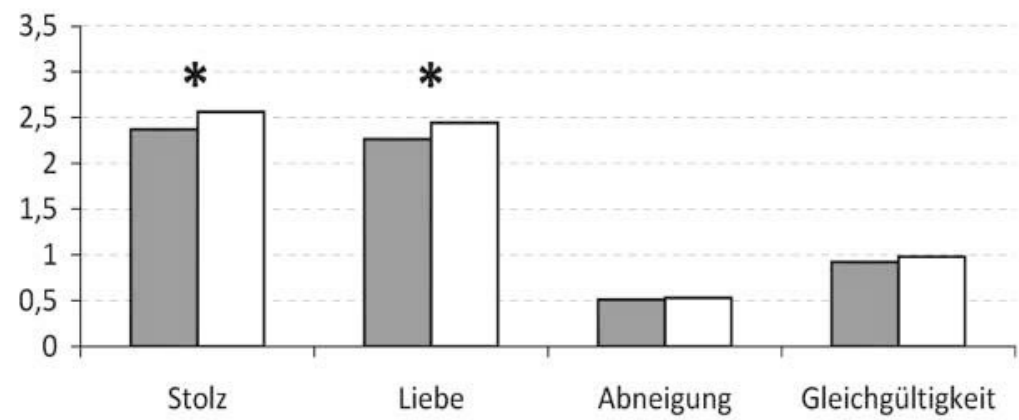

$\square$ West $\quad$ Oost

Abbildung 14: Gefühle gegenüber der deutschen Sprache (nach Herkunft) - Vergleich der Mittelwerte (Fragen wie Abbildungen 12 und 13)

Ähnlich wie bei den Antworten auf die Frage nach dem Sprachgefallen (vgl. oben Abschnitt 3.1) spielen aber bei den emotionalen Einstellungen gegenüber der deutschen Sprache andere Faktoren eine bedeutendere Rolle. Wenn man die gegebenen Antworten nicht nach Herkunft der Befragten gruppiert, sondern nach anderen soziodemographischen Faktoren oder danach, wie auf bestimmte andere Fragen geantwortet wurde, lässt sich das Bild etwas präzisieren. Statistisch gesehen sind es einerseits Alter und Bildung, andererseits politische Einstellungen, die einen Einfluss auf die positiven Emotionen gegenüber der deutschen Sprache haben (Abbildung 15). ${ }^{16}$

14 Damit korrespondieren auch die Daten einer Erhebung, die jüngst im Auftrag der Identity FoundationStiftung durchgeführt wurde (vgl. Identity Foundation 2009) und die u.a. zu dem Ergebnis kommt: ,,59,3 Prozent aller Deutschen sagen heute von sich: 'Ich bin stolz, Deutsche/r zu sein.' (...) 79,6 Prozent der Bevölkerung sind sich sicher, dass es ein Wesenszug der Deutschen ist, ihr Vaterland zu lieben." (Identity Foundation 2009, S. 14).

15 Einen ähnlichen Hinweis gibt allerdings auch die erwähnte Erhebung der Identity Foundation, wenn dort festgestellt wird: „Das Nationalgefühl ist in den neuen Bundesländern etwas größer als in den alten.“ (Identity Foundation 2009, S. 38).

16 Diese Abbildung ist wie folgt zu lesen: Für diese Darstellung wurde die Gruppe der Befragten nach den Antworten, die sie auf die betreffende Frage gegeben haben, in Untergruppen eingeteilt, nämlich einerseits Personen, die in höherem Maße Stolz (bzw. Liebe) für die deutsche Sprache empfinden, und solche, die in geringerem Maße Stolz (bzw. Liebe) für die deutsche Sprache empfinden. Das bedeutet, dass Per- 

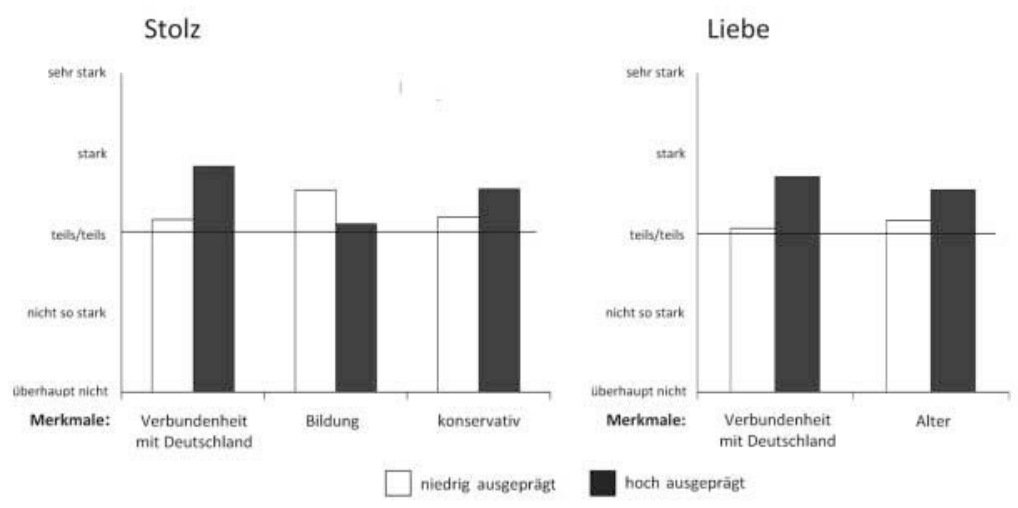

Abbildung 15: Stolz/Liebe, nach Alter, Bildung, politischen Einstellungen (Fragen wie Abbildung 12)

Demnach empfinden vor allem Personen, die angeben, sich stark mit Deutschland verbunden zu fühlen, und Personen, die konservativer sind, in hohem Maße Stolz; außerdem geben Personen mit einem niedrigeren Bildungsabschluss eher an, sie empfänden Stolz in Bezug auf die deutsche Sprache. Die Verbundenheit mit Deutschland ist auch bei der Frage nach der Liebe zur deutschen Sprache ein maßgeblicher Faktor; außerdem geben statistisch gesehen ältere Personen eher an, dass sie Liebe empfinden. Das Geschlecht der Befragten ist übrigens auch hier statistisch nicht signifikant (vgl. Eichinger et al. 2009, S. 9-11).

\subsection{Der typische Deutsche}

Auch wenn sich die mit bestimmten Sprachen oder Sprachformen verbundenen Stereotypen oder Emotionen auf die gezeigte Weise sinnvoll erheben lassen, darf nicht übersehen werden, dass die Wahrnehmung von Sprache - und damit auch die Einstellungen zu ihr - niemals isoliert-abstrakt erfolgt; die Bewertung eines Sprachverhaltens ist immer mit den Sprechern bzw. der Sprechergruppe verbunden. Daher beeinflussen auch die Einstellungen zu bestimmten Personengruppen die Beurteilung der Varietät, die sie sprechen; Einstellungen zur eigenen Sprache und zu fremden Sprachen basieren nicht nur - oder vielleicht nicht einmal in erster Linie - auf sprachinhärenten Merkmalen, sondern auch auf stereotypen Vorstellungen über die zugehörigen Sprechergruppen (Zahn/Hopper 1985).

sonen, die sich stark mit Deutschland verbunden fühlen (erster dunkler Balken), eher angeben, dass sie Stolz für die deutsche Sprache empfinden, als Personen, die sich weniger stark mit Deutschland verbunden fühlen (erster heller Balken). Der helle Balken gibt stets eine niedrigere Ausprägung des Merkmals (hier z.B. Verbundenheit mit Deutschland) an, der dunkle steht entsprechend für eine hohe Ausprägung des Merkmals. Die Einteilung in zwei Gruppen erfolgt über eine Medianhalbierung. Die Höhe der Balken zeigt also die durchschnittliche Einschätzung bezüglich der entsprechenden Frage (Stolz bzw. Liebe) an. 
Aus diesem Grund wurden, wiederum vermittels geeignet gewählter semantischer Differentiale (freundlich, gebildet und temperamentvoll), die Einstellungen, die die Befragten $\mathrm{zu}$,dem typischen Deutschen“ haben, erhoben (Abbildung 16). ${ }^{17}$

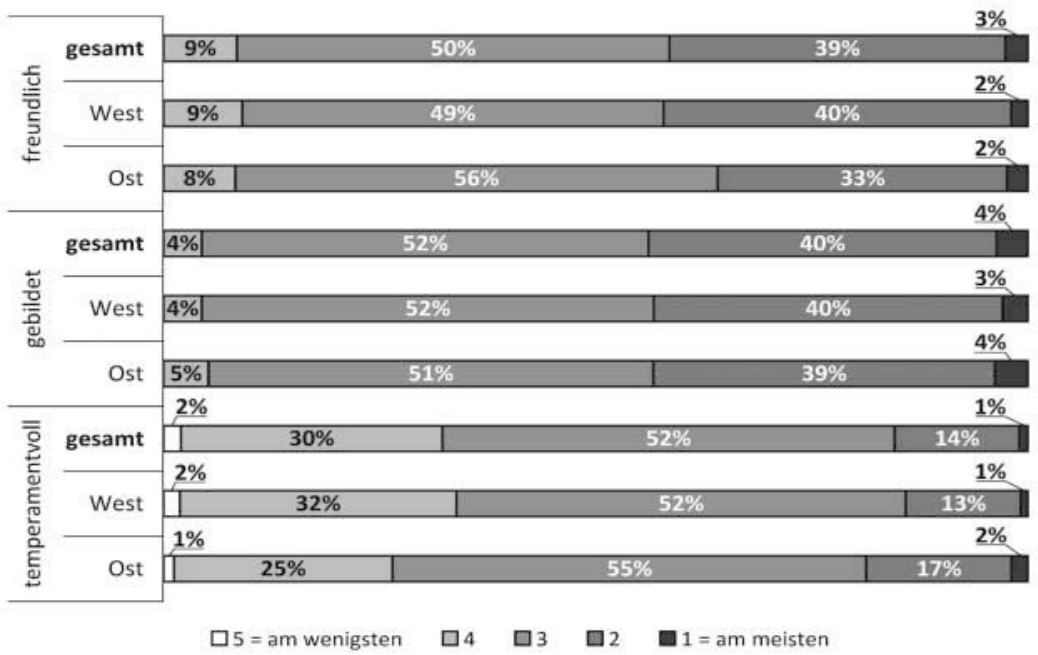

Abbildung 16: Der typische Deutsche (nach Herkunft)

Fragen: Und jetzt nach der Sprache zu den Menschen: Was meinen Sie zu folgenden Eigenschaften: Ist der typische Deutsche Ihrer Meinung nach ... bzw. Ist die typische Deutsche Ihrer Meinung nach ... a) sehr freundlich, freundlich, teils/teils, unfreundlich, sehr unfreundlich, weiß nicht/keine Angabe? und b) sehr gebildet, gebildet, teils/teils, ungebildet, sehr ungebildet, weiß nicht/keine Angabe? und c) sehr temperamentvoll, temperamentvoll, teils/teils, ruhig, sehr ruhig, weiß nicht/keine Angabe? (Stichprobe geteilt)

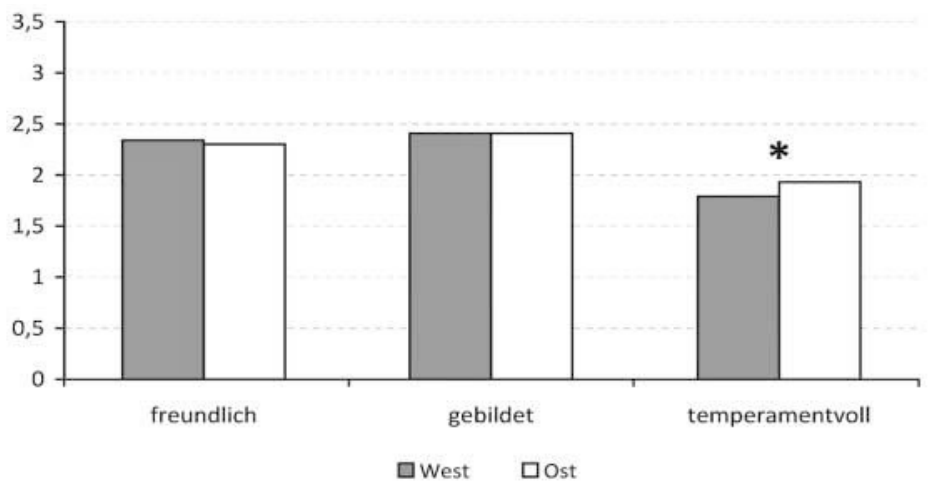

Abbildung 17: Der typische Deutsche (nach Herkunft) - Vergleich der Mittelwerte (Fragen wie Abbildung 16)

17 Diese Fragereihe wurde einem Teil der Stichprobe in generischer Formulierung gestellt („Ist der typische Deutsche Ihrer Meinung nach ...") und dem anderen Teil der Stichprobe als Beidnennung (,Ist die typische Deutsche bzw. der typische Deutsche Ihrer Meinung nach ..."). Allerdings ergaben sich daraus keine relevanten Unterschiede, sodass die beiden Gruppen für diese Darstellung wieder zusammengeführt wurden. 
Wie auch die Darstellung des Vergleichs der Mittelwerte zeigt (Abbildung 17), sind auch hier die Unterschiede zwischen Ost und West nicht groß. Einzig beim Merkmal temperamentvoll wird der Unterschied statistisch signifikant (mit einem Mittelwert von 1,79 im Westen gegenüber 1,93 im Osten); auch diese Differenz ist jedoch nicht erheblich.

Die hier eingesetzten semantischen Differentiale kommen auch noch einmal bei der Erhebung der Einstellungen gegenüber Bayern und Sachsen (als Repräsentanten besonders prominenter arealer Varietäten des Deutschen) zum Tragen (vgl. unten Abschnitt 6.1).

\section{Sprachgebrauch}

In Kapitel 3 wurde gezeigt, dass sich die Menschen in Ost und West in ihren allgemeinen Einstellungen zur Sprache und zum Deutschen zwanzig Jahre nach dem Fall der Mauer insgesamt kaum unterscheiden. In diesem Kapitel sollen diejenigen Teile der Erhebung vorgestellt werden, in denen konkrete Verwendungsweisen des Deutschen thematisiert wurden. Zunächst geht es um die allgemeine Sorgfalt beim Sprechen, beim Schreiben und in der Anwendung der Rechtschreibregeln (Abschnitt 4.1). Danach werden Fragen zur Entwicklung der Sprache, zur Wahrnehmung sprachlicher Veränderungen und deren Bewertung vorgestellt (Abschnitt 4.2). Der letzte Abschnitt behandelt Fragen der Sprachpolitik und eventuelle Maßnahmen zum Schutz der deutschen Sprache (Abschnitt 4.3). Es zeigt sich, dass sich in diesem Bereich durchaus gewisse Unterschiede zwischen Ost und West abzeichnen, die insgesamt in eine ähnliche Richtung zu deuten scheinen.

\subsection{Sprachsorgfalt}

Es besteht in Deutschland ein sehr breiter gesellschaftlicher Konsens darüber, dass die deutsche Sprache mit Sorgfalt und Umsicht zu behandeln sei. Sorgfalt beim Sprechen, Sorgfalt beim Schreiben und (was nicht dasselbe ist) die Beachtung der Rechtschreibregeln wird jeweils von einer überwältigenden Mehrheit für „wichtig“ oder „sehr wichtig“ gehalten (Sorgfalt beim Sprechen 92,2 Prozent, Sorgfalt beim Schreiben sogar 94,9 Prozent, Rechtschreibung dagegen nur - oder immerhin noch - 81,5 Prozent); die Werte sind in Ost wie West sehr hoch (Abbildung 18). 


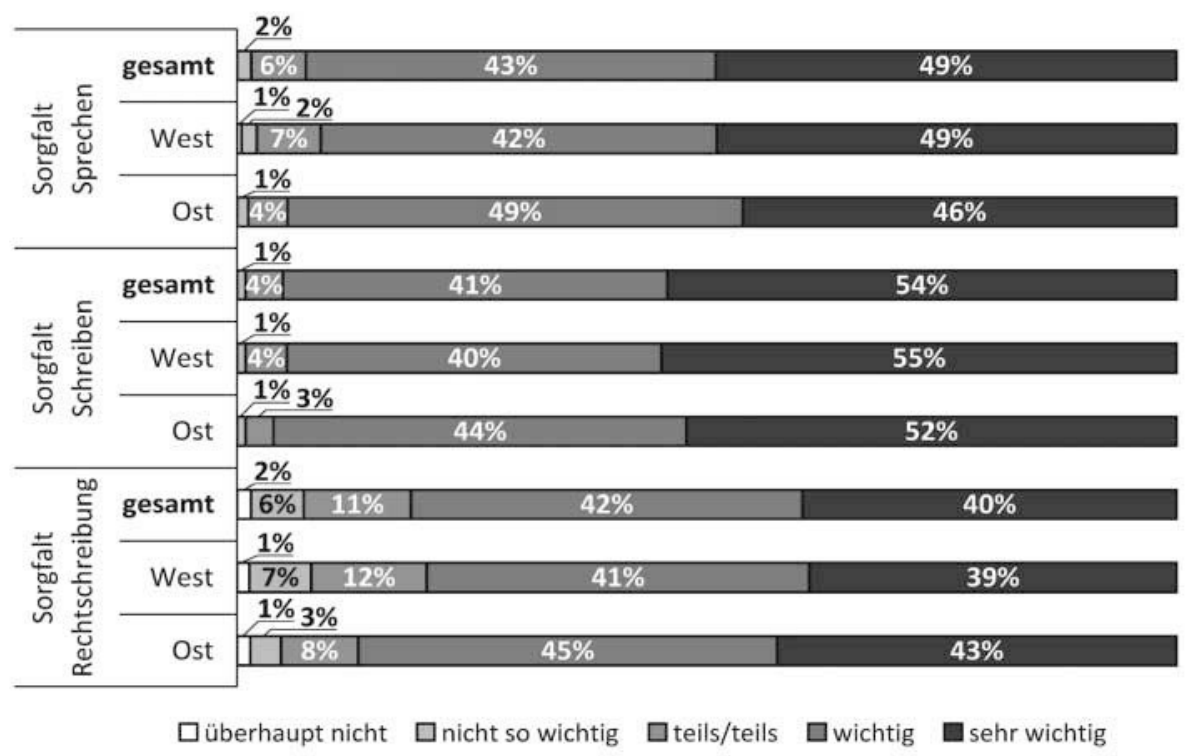

Abbildung 18: Sorgfalt beim Sprechen, beim Schreiben und bei der Rechtschreibung (nach Herkunft)

Fragen: Für wie wichtig halten Sie es, dass man sich beim Sprechen der deutschen Sprache sorgfältig ausdrückt? Halten Sie das für ... (sehr wichtig, wichtig, teils/teils, nicht so wichtig, überhaupt nicht wichtig, weiß nicht/keine Angabe)? und Und für wie wichtig halten Sie es, dass man sich beim Schreiben der deutschen Sprache sorgfältig ausdrückt? Halten Sie das für ... (sehr wichtig, wichtig, teils/teils, nicht so wichtig, überhaupt nicht wichtig, weiß nicht/keine Angabe)? und Und für wie wichtig halten Sie es, dass man beim Schreiben der deutschen Sprache die Rechtschreibregeln beachtet? Halten Sie das für ... (sehr wichtig, wichtig, teils/teils, nicht so wichtig, überhaupt nicht wichtig, weiß nicht/keine Angabe)?

Während die Sorgfalt beim Sprechen und beim Schreiben für die Befragten in Ost und West gleichermaßen bedeutend ist, unterscheiden sich die Befragten, wie der Vergleich der Mittelwerte veranschaulicht, signifikant bei der Bewertung des Stellenwerts der Beachtung der Rechtschreibregeln: Die Befragten im Osten halten es für wichtiger, dass man beim Schreiben der deutschen Sprache die Rechtschreibregeln beachtet (Abbildung 19).

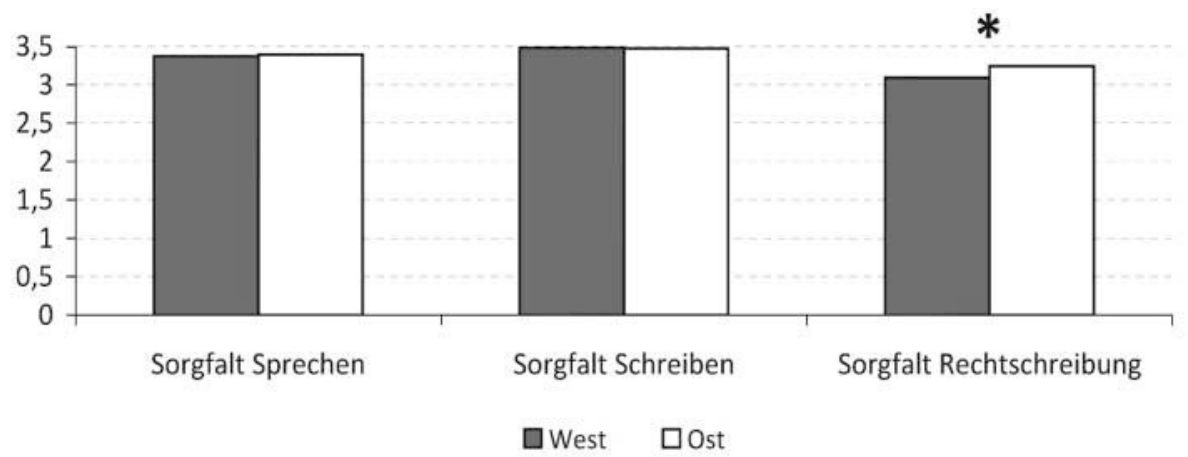

Abbildung 19: Sorgfalt beim Sprechen, beim Schreiben und bei der Rechtschreibung (nach Herkunft) - Vergleich der Mittelwerte (Fragen wie Abbildung 18) 
Auch hier ist allerdings festzuhalten, dass es eine ganze Reihe anderer Faktoren gibt, die bei diesen Fragen eine Rolle spielen. Die Werte für alle drei Fragen sind insgesamt bei Frauen höher als bei Männern; außerdem fallen sie statistisch höher aus bei denjenigen Personen, die angeben, dass sie ein höheres allgemeines Sprachinteresse haben; ferner bei denen, die sich stärker mit Deutschland verbunden fühlen, und bei denen, die mehr Liebe für die deutsche Sprache empfinden. Sorgfalt beim Sprechen und Sorgfalt beim Schreiben sind im Übrigen für Personen, die einen höheren Bildungsabschluss haben, besonders wichtig (vgl. Eichinger et al. 2009, S. 44-46).

\subsection{Sprachentwicklung}

Ein Punkt, an dem sich öffentliche Diskussionen, in denen die Sprache Thema ist, regelmäßig entzünden, ist ihre Historizität. Im laienlinguistischen Diskurs findet dabei oft und in der Regel aus einer kritischen Perspektive - eine Fokussierung auf den gegenwärtigen oder rezenten Sprachwandel statt, der vielfach als Bedrohung oder auch als Indiz eines generellen kulturellen Degenerationsprozesses bewertet wird (vgl. z.B. Schrodt 1995). Insofern ist es durchaus nicht überraschend, dass die Frage nach aktuellen Veränderungen in der deutschen Sprache von einer sehr großen Mehrheit der Befragten bejaht wird (Abbildung 20). ${ }^{18}$

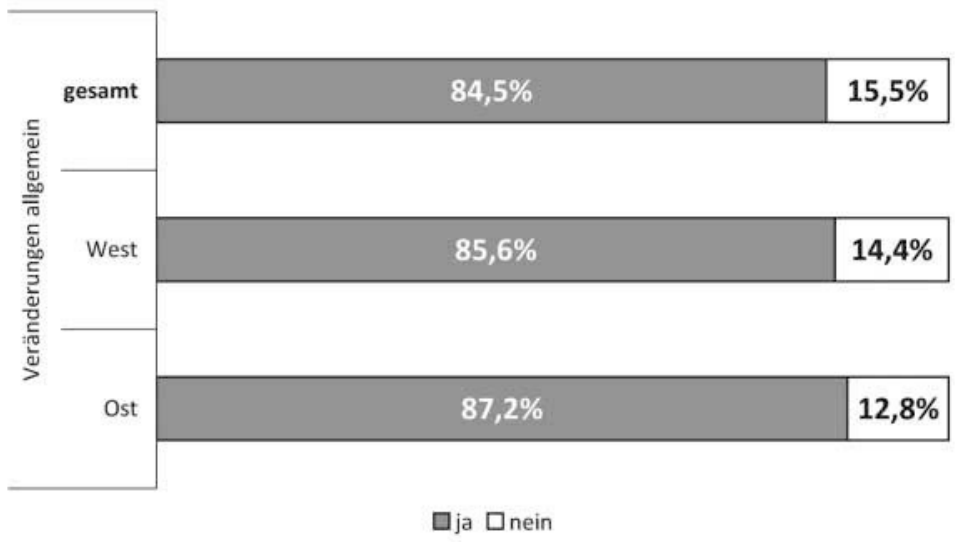

Abbildung 20: Wahrnehmung von Veränderungen in der deutschen Sprache (nach Herkunft)

Frage: Sind Ihnen in den letzten Jahren Veränderungen in der deutschen Sprache aufgefallen, oder sind Ihnen keine Veränderungen aufgefallen?

Einen statistisch signifikanten Unterschied zwischen den Befragten in Ost- und Westdeutschland gibt es bei dieser Frage nicht. ${ }^{19}$ Auch das Alter der Befragten spielt statistisch gesehen keine Rolle. Ein entscheidender Faktor ist hingegen beispielsweise (was unmit-

18 Erheblich niedriger als heute waren die Werte allerdings bei der IDS-Umfrage von 1997/98: hier antworteten auf die entsprechende (leicht anders formulierte) Frage nur 46,6 Prozent mit ,ja“, 53,4 Prozent hingegen mit „nein“ (Stickel/Volz 1999, S. 17-18).

19 Auch das war vor zehn Jahren noch anders (wobei allerdings die Werte damals nicht auf statistische Signifikanz getestet wurden): 1997/98 gaben 51,9 Prozent der Befragten im Osten, aber nur 45,2 Prozent im Westen an, Veränderungen bemerkt zu haben (Stickel/Volz 1999, S. 17-18). 
telbar plausibel erscheinen mag) der Bildungsabschluss: Von den Befragten mit Hochschulabschluss geben 95,3 Prozent an, Veränderungen bemerkt zu haben, von den Befragten mit Abitur sind es 94,7, von den Befragten mit Mittlerer Reife sind es 86,2 Prozent und von den Befragten mit Hauptschulabschluss 77,4 Prozent. Auch Personen mit einem höheren allgemeinen Sprachinteresse sowie Personen mit einer weniger konservativen politischen Orientierung bemerken sta-tistisch eher sprachliche Veränderungen (vgl. Eichinger et al. 2009, S. 35-36).

Ähnlich wie sich, wie oben erwähnt, der nichtlinguistische Diskurs über die sprachlichen Unterschiede zwischen Ost und West vornehmlich aus (tatsächlichen oder auch nur vermeintlichen) Wortschatzdifferenzen speist, konzentriert sich ein Gutteil des sprachkritischen Diskurses der interessierten Öffentlichkeit auf Veränderungen im Lexikon. Daher wurden diejenigen, die angeben, dass ihnen Veränderungen aufgefallen sind, weiter erstens nach Wörtern oder Redewendungen aus anderen Sprachen und zweitens nach neuen deutschen Wörtern oder Redewendungen gefragt (Abbildung 21). Erwartungsgemäß sind die Werte für die fremden Wörter (man darf vermuten: vorwiegend Anglizismen) sehr hoch; neue deutsche Wörter oder Redewendungen werden von etwas mehr als der Hälfte der Befragten wahrgenommen. Auch hier werden die Unterschiede zwischen ostdeutschen und westdeutschen Befragten statistisch nicht signifikant.

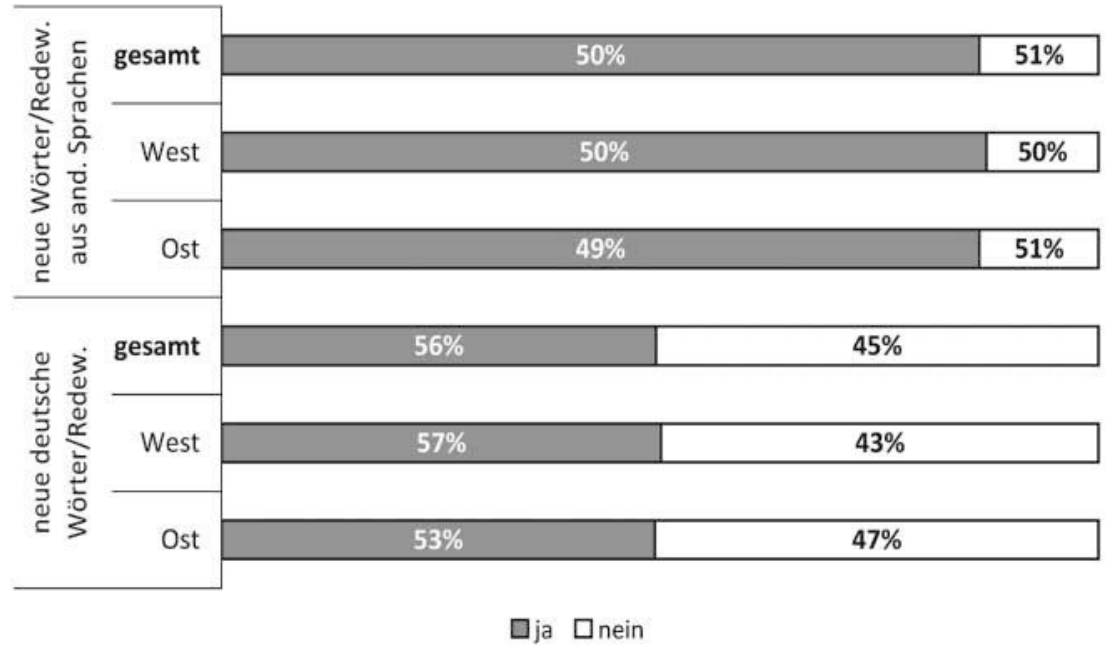

Abbildung 21: Neue Wörter oder Redewendungen (nach Herkunft)

Fragen: Sind Ihnen da neue Wörter oder Redewendungen aus anderen Sprachen aufgefallen? und Und sind Ihnen da neue deutsche Wörter oder Redewendungen aufgefallen?

Anschließend wurde denjenigen, die angaben, Veränderungen bemerkt zu haben, die Frage gestellt, ob ihnen sonstige Veränderungen (d.h. abgesehen von Wörtern und Redewendungen) aufgefallen seien (Abbildung 22). Die Frage wurde von einer deutlichen Mehrheit bejaht; auch hier sind die Unterschiede zwischen Ost und West nicht groß (Westdeutschland: 57,3 Prozent, Ostdeutschland: 53,2 Prozent; der Unterschied wird statistisch nicht signifikant). 


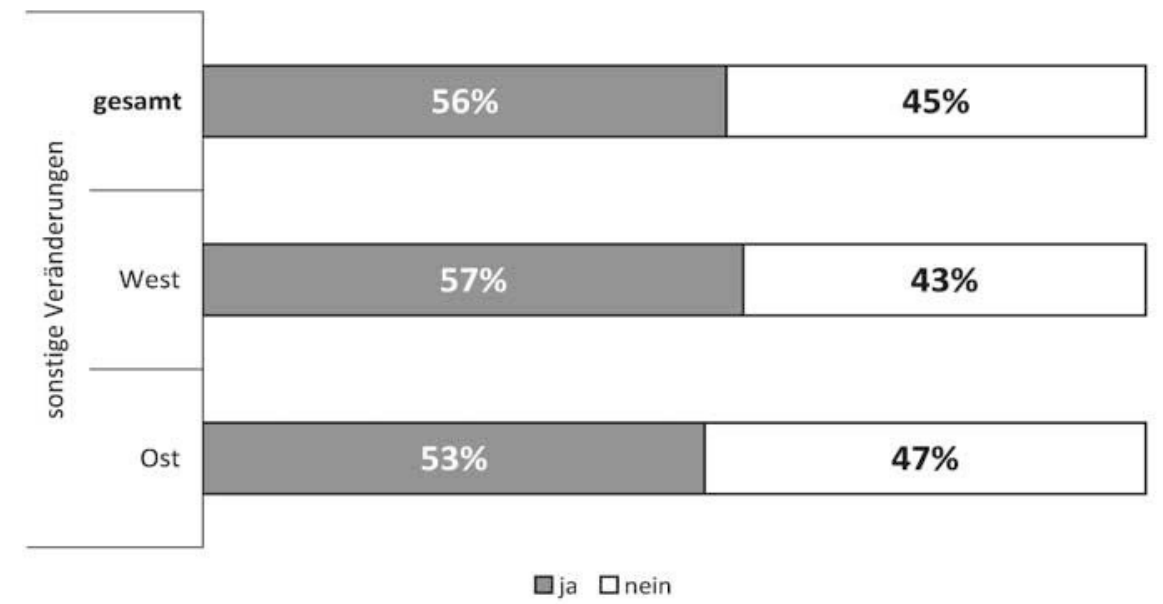

Abbildung 22: Wahrnehmung sonstiger Veränderungen in der deutschen Sprache (nach Herkunft)

Frage: Und sind Ihnen sonstige Veränderungen aufgefallen?

In diesem Bereich gibt es allerdings tatsächlich Unterschiede zwischen Ost und West, die jedoch unter der einfachen Dichotomie der Ja-Nein-Frage nicht sichtbar werden. Diejenigen, die diese Frage positiv beantwortet haben, wurden weiter gefragt, um welche Veränderungen es sich handle (Tabelle 1). Diese Frage war offen gestellt, d.h. es wurde nicht eine Liste von vorgegebenen Items abgefragt, sondern die Antworten wurden von den Befragten frei formuliert (und es waren Mehrfachantworten möglich). Diese Methode hat den großen Vorteil, dass mit ihr aktives Wissen abgefragt werden kann, weil die Befragten nicht mit Echoformen auf präformulierte Kategorien reagieren, sondern selber Kategorien schaffen müssen. Darin liegt jedoch zugleich auch ihre größte Schwierigkeit: die Auswertung der Daten erweist sich nicht nur als außerordentlich mühselig und zeitaufwendig, sondern vor allem auch als inhaltlich nicht trivial. Um verwertbare Aussagen treffen zu können, müssen die gegebenen Antworten in Gruppen zusammengefasst und kategorisiert werden. Dabei treten unweigerlich Kategorienunschärfen und Abgrenzungsprobleme auf, weil die Antworten logisch auf sehr unterschiedlichen Ebenen liegen können (von der Nennung von Einzelwörtern bis zu globaler Kulturkritik) und weil sie von einem sehr unterschiedlichen Präzisionsgrad sind. Hinzu kommt, dass man sich, wo Fachbegriffe gebraucht werden, ihrer Terminologizität niemals ganz sicher sein kann. Nicht zuletzt kommt es auch zu Doppelungen innerhalb der Kategorien und zu Überschneidungen mit den vorangegangenen Fragen (nicht wenige Befragte nennen die eigentlich ja schon abgefragten Wörter aus fremden Sprachen ausdrücklich noch einmal). Insofern ist bei der Kategorienbildung ein gewisser Grad an Willkür unvermeidlich; die Ergebnisse sind in Bezug auf die hier verfolgte Ost-West-Fragestellung gleichwohl aufschlussreich. ${ }^{20}$

20 Die Mehrfachantworten auf diese offene Frage konnten nicht auf statistische Signifikanz hin getestet werden. 


\begin{tabular}{lccc}
\hline & gesamt & West & Ost \\
\hline Einflüsse durch fremde Sprachen & 28,1 & 25,3 & 37,1 \\
\multicolumn{1}{c}{. davon Einflüsse aus } & 21,0 & 18,0 & 31,9 \\
$\quad$ England/Amerika & 24,8 & 23,4 & 24,5 \\
(neue) Rechtschreibung & 14,8 & 16,6 & 10,4 \\
Jugendsprache & 11,7 & 11,3 & 14,9 \\
Mangelnde Sprachsorgfalt & 7,2 & 8,6 & 4,1 \\
Veränderungen der Grammatik & 5,4 & 5,6 & 5,5 \\
Verkümmerung der Sprache & 4,8 & 4,7 & 5,5 \\
Veränderter Umfang des Wort- & 3,5 & 3,6 & 3,9 \\
schatzes & 3,0 & 3,6 & 1,5 \\
Lexikalische Abkürzungen & 2,3 & 2,9 & 0,9 \\
Vereinfachender Gebrauch in den & 2,2 & 2,3 & 1,6 \\
neuen Medien (SMS, Internet) & 2,2 & 2,5 & 1,2 \\
Syntaktische Verkürzungen & 1,6 & 1,7 & 1,3 \\
Veränderte Stellung der Dialekte & 1,6 & 1,2 & 3,2 \\
Geringer Stellenwert des Deutschen & 1,5 & 1,6 & 1,2 \\
Vereinfachung der Sprache & 2,0 & 2,3 & 1,4 \\
Aussprache & 1,0 & 1,0 & 1,3 \\
Vulgär-/Fäkalsprache & 3,7 & 3,8 & 2,4 \\
Soziolekte/Fachsprachen & Bedeutungswandel & &
\end{tabular}

Tabelle 1: Wahrgenommene Veränderungen, nach Herkunft (Angaben in Prozent)

Frage: Und was für Veränderungen sind das?

Bei vielen Kategorien - etwa der Rechtschreibung oder bei den Meldungen, die sich auf eine „Verkümmerung der Sprache“ beziehen - liegen Ost und West wiederum sehr dicht beieinander. Auffällig ist allerdings, dass der Einfluss fremder Sprachen und hier besonders des Englischen von den Befragten im Osten erheblich häufiger genannt wird (31,9 Prozent im Osten gegenüber 18,0 Prozent im Westen). Das mag man als Reflex veränderter Kommunikationsgewohnheiten seit der Wende, in deren Folge die Präsenz englisch-amerikanischer Sprachformen in Ostdeutschland gestiegen sein dürfte, werten. Allerdings weist Hellmann (2000, S. 265) darauf hin, dass trotz der offiziellen Kritik angloamerikanische Ausdrücke auch in der DDR Eingang in den allgemeinen Sprachgebrauch besonders der Jüngeren gefunden haben und der offizielle Widerstand dagegen schon seit den 80er-Jahren nachließ.

Auch wenn in diesen Fragen immer nur neutral nach Veränderungen gefragt wurde, legen die meisten Äußerungen einen kritischen Subtext zumindest nahe. Das gilt beispielsweise erkennbar für die Kategorie Jugendsprache, die zwar auch eine Reihe nur beschreibende, überwiegend jedoch distanzierende Meldungen enthält. Hier sind es deutlich mehr Befragte im Westen (16,6 Prozent) als im Osten (10,4 Prozent), die jugendsprachliche Gebrauchsweisen als aktuelle Veränderungen wahrnehmen. 
Explizit kulturkritische Äußerungen (mangelnde Sprachsorgfalt) finden sich wiederum häufiger im Osten (14,9 Prozent) als im Westen (11,3 Prozent); das mag mit den in den Abbildungen 18 und 19 dargstellten Ergebnissen in Zusammenhang gebracht werden (obgleich bei dieser Frage gerade bei der Rechtschreibung keine nennenswerten Unterschiede festzustellen sind).

Diejenigen, die diese Frage beantwortet haben, wurden, wiederum in einer offenen Frage, die Mehrfachantworten zuließ, nach den Verursachern der von ihnen genannten Veränderungen gefragt (Tabelle 2). Auch hier ist die Grenzgültigkeit der gewählten Kategorien nur eine relative; dennoch lassen sich aus der Tabelle einige Dinge ablesen.

\begin{tabular}{lccc}
\hline & gesamt & West & Ost \\
\hline Medien (Fernsehen, Radio, & 37,0 & 37,3 & 38,1 \\
Zeitungen) & 26,3 & 26,3 & 25,7 \\
Ausländer, Migranten & 21,7 & 24,5 & 15,2 \\
Jugendgruppen, -kultur & 16,2 & 16,3 & 14,1 \\
Einfluss anderer Kulturen und & 15,7 & 15,9 & 16,1 \\
Sprachen & 13,2 & 13,0 & 15,4 \\
Neue Medien (Computer, Handy) & 8,2 & 7,3 & 10,2 \\
Globalisierung & 7,6 & 7,2 & 9,9 \\
Politik und Wirtschaft & 5,0 & 5,1 & 5,3 \\
Schule, Schulpolitik & 4,4 & 4,1 & 6,6 \\
Nachlässiger Umgang mit Sprache & 4,3 & 4,5 & 2,7 \\
Werbung & 4,1 & 3,9 & 3,9 \\
Internationale Kontakte & 2,9 & 3,2 & 2,9 \\
Normale Veränderungen der Sprache & 2,7 & 2,6 & 3,0 \\
Musik und Mode & 1,8 & 1,9 & 1,4 \\
Neue Technik, neue Bezeichnungen & 1,7 & 1,7 & 1,7 \\
Soziales Umfeld: Eltern, Freunde & 5,2 & 4,2 & 8,2 \\
Auslandsaufenthalte & Sonstiges &
\end{tabular}

Tabelle 2: Veränderungsursachen, nach Herkunft (Angaben in Prozent)

Frage: Durch wen oder was werden Ihrer Meinung nach Veränderungen in der deutschen Sprache verursacht? (Mehrfachnennung möglich)

Die auffälligste Ost-West-Differenz betrifft die angenommene Verantwortlichkeit von Jugendgruppen, Jugendkultur usw. für sprachliche Veränderungen, die im Westen erheblich höher veranschlagt wird (24,5 Prozent) als im Osten (15,2 Prozent). Das ist durchaus stimmig mit den Ergebnissen der vorangegangenen Frage (Tabelle 1), wo im Westen wesentlich mehr jugendsprachliche Elemente als sprachliche Veränderungen genannt wurden. In allen anderen Bereichen liegen die Befragten in Ost und West, wieder einmal, sehr dicht beieinander; eine prinzipielle Kluft zwischen den alten und den neuen Bundesländern in der Einschätzung aktueller Sprachwandelprozesse ist nicht festzustellen. 


\subsection{Sprachpolitik}

Das laienlinguistische Nachdenken über Sprache erfolgt, vor allem im gebildeten Bürgertum, nicht selten in der Form von Kritik am Sprachgebrauch der Anderen, flankiert von einem zumindest segmentalen Kulturpessimismus. Dementsprechend ist auf die allgemeine Frage nach der Bewertung der derzeitigen Entwicklung der deutschen Sprache nur wenig Euphorie zu erwarten (Abbildung 23).

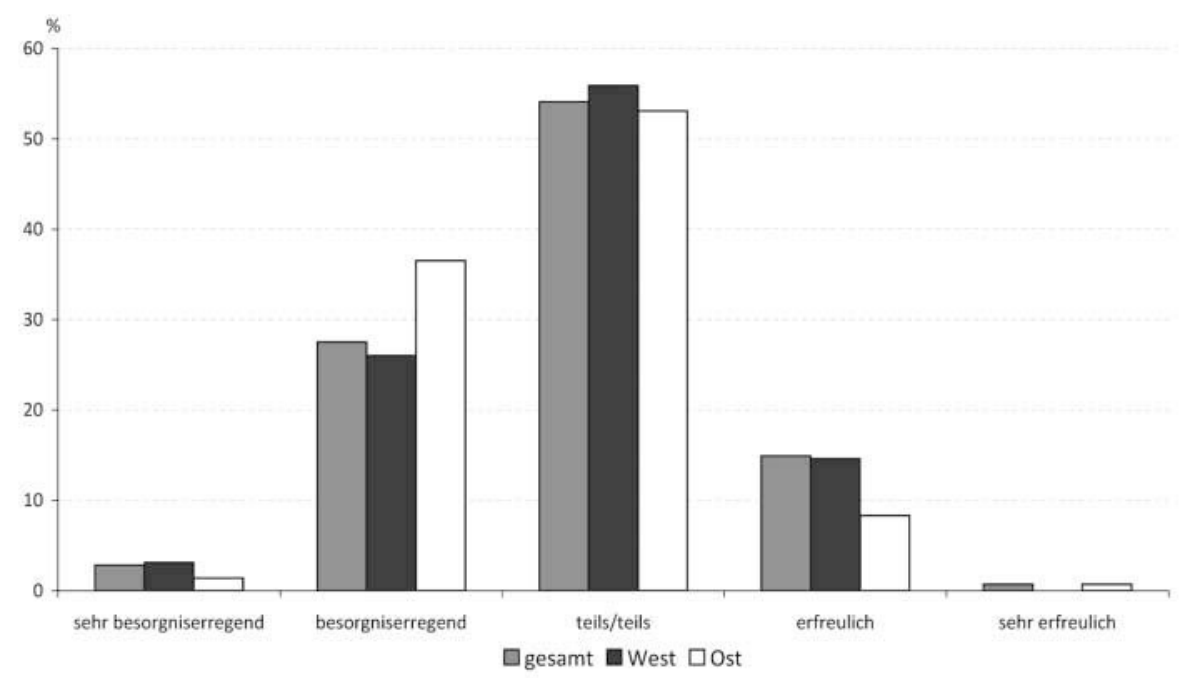

Abbildung 23: Bewertung der Entwicklung der deutschen Sprache (nach Herkunft)

Frage: Einmal alles zusammen genommen: Finden Sie die derzeitige Entwicklung der deutschen Sprache... (sehr erfreulich, erfreulich, teils/teils, besorgniserregend, sehr besorgniserregend)?

Wenig überraschend ist hier die Bewertung mit „teils/teils“ dominant; explizit besorgt sind im Bundesdurchschnitt 30,3 Prozent der Befragten. Allerdings gibt es an dieser Stelle einen deutlichen Unterschied zwischen Ostdeutschen und Westdeutschen: Im Westen wird die Entwicklung insgesamt als erfreulicher eingeschätzt als im Osten. Dieser Unterschied ist auch statistisch signifikant (die Mittelwerte liegen bei 1,83 für den Westen gegenüber 1,70 für den Osten).

Dass die eigene Sprache etwas ist, mit dem man sich positiv identifiziert, wird nicht nur bei den oben berichteten Fragen zu den Emotionen deutlich (vgl. Abbildung 12), sondern auch in diesem Kontext. Die sehr allgemein gehaltene Frage, ob mehr für die deutsche Sprache getan werden sollte, wird so pauschal von über vier Fünfteln der Befragten bejaht (im Osten sind die Werte wiederum signifikant höher als im Westen). Zunächst muss das aber noch nicht mehr sein als ein Indiz für ein prinzipielles Einvernehmen; unmittelbare politische Konsequenzen in Form eines Sprachschutzgesetzes fordert nämlich insgesamt nur eine Minderheit (39,5 Prozent) (Abbildung 24). 


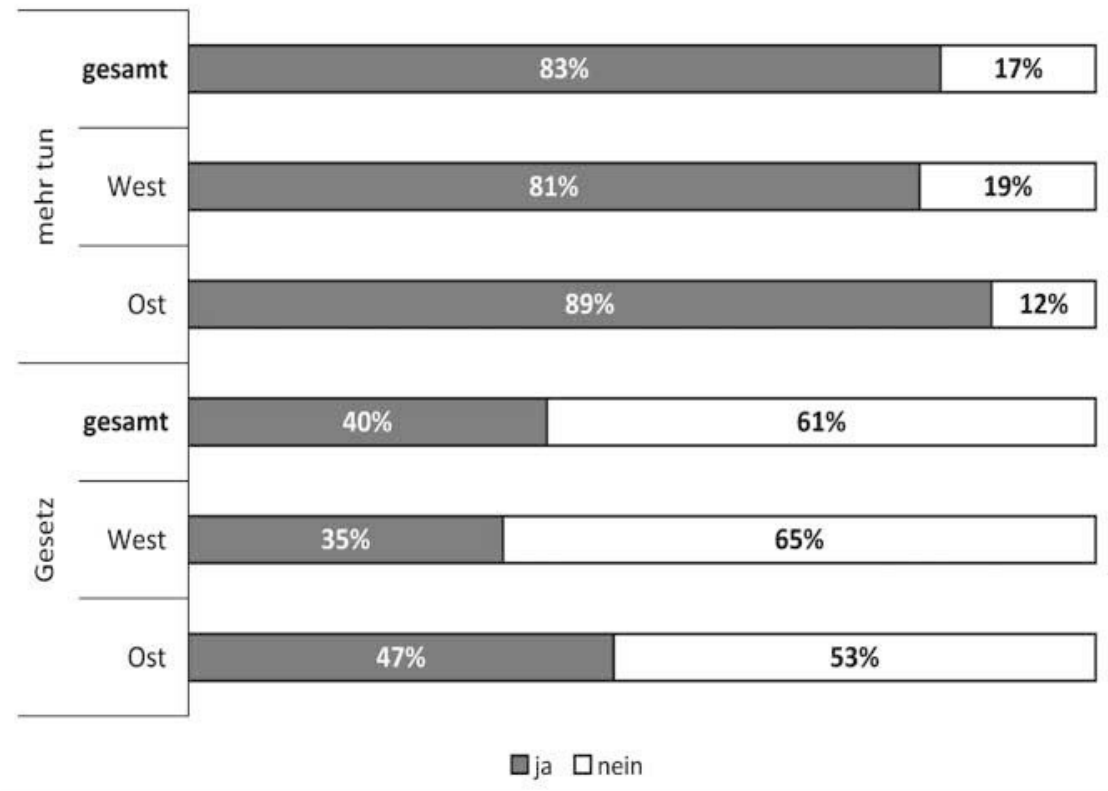

Abbildung 24: Schutz der deutschen Sprache (nach Herkunft)

Fragen: Einmal ganz allgemein gefragt: Sollte Ihrer Meinung nach mehr für die deutsche Sprache getan werden? und Halten Sie es für notwendig, dass die deutsche Sprache durch ein Gesetz vor möglichen negativen Einflüssen geschützt wird, oder halten Sie das nicht für notwendig?

Differenziert man die Befragten nach ihrer Herkunft, zeigt sich, dass der Anteil der Befragten, die ein Gesetz zum Schutz der deutschen Sprache für notwendig halten, im Osten mit 46,9 Prozent signifikant höher ist als im Westen (34,7 Prozent). Allerdings ist auch bei dieser Frage die Herkunft nur ein Faktor unter mehreren. Es lassen sich auch Korrelationen zu anderen Einstellungen ermitteln, beispielsweise sind statistisch gesehen häufiger solche Personen für ein Sprachschutzgesetz, die sich mit Deutschland stärker verbunden fühlen und die in besonderem Maße Stolz für die deutsche Sprache empfinden. Darüber hinaus ist die Beantwortung der Frage nach dem Sprachschutzgesetz stark bildungskorreliert: Je höher der Bildungsabschluss, desto eher werden sich die Befragten gegen ein solches Gesetz aussprechen (79,6 Prozent der Befragten mit Hochschulabschluss, 75,0 Prozent der Befragten mit Abitur, 63,5 Prozent der Befragten mit Mittlerer Reife, 49,1 Prozent der Befragten mit Hauptschulabschluss); umgekehrt sprechen sich eher Personen für ein Sprachschutzgesetz aus, die seltener deutsche Bücher und deutsche Internetbeiträge lesen (vgl. Eichinger et al. 2009, S. 46-48).

An die Frage, ob mehr fürs Deutsche getan werden sollte, schloss sich (bei Zustimmung) die Frage an, wem denn diese Aufgabe zukomme (Tabelle 3). Auch diese Frage war wieder offen gestellt; es ergeben sich auch hier die genannten Auswertungs- und Kategorisierungsprobleme. 


\begin{tabular}{lccc}
\hline & gesamt & West & Ost \\
\hline Lehrer, Schule, Jugend- & 68,1 & 71,3 & 64,7 \\
zentren usw. & 35,8 & 36,3 & 37,4 \\
Politik & 26,1 & 29,6 & 19,4 \\
Eltern & 11,6 & 12,8 & 9,1 \\
Kindergarten & 13,3 & 12,6 & 15,4 \\
Medien & 11,4 & 10,2 & 16,5 \\
Wissenschaft & 10,3 & 9,8 & 8,3 \\
Gesellschaft/Bürger/jeder & 3,2 & 2,9 & 4,2 \\
selbst & 6,9 & 7,6 & 7,0 \\
Wirtschaft/Unternehmen & Sonstige &
\end{tabular}

Tabelle 3: Zuständige Instanzen, nach Herkunft (Angaben in Prozent)

Frage: Und wer sollte sich darum besonders kümmern? (Mehrfachnennung möglich)

Insgesamt zeugen die Antworten von einem breiten Vertrauen in die Institutionen. An erster Stelle und mit großem Abstand, von rund zwei Dritteln der Befragten, wird die Schule genannt; sie ist offenbar nach wie vor die zentrale Instanz, die mit der Verbreitung von literacy betraut ist - und der man das auch zutraut. Ein auffälliger West-Ost-Unterschied besteht darin, dass die Eltern im Westen von wesentlich mehr Befragten genannt werden (29,6 Prozent) als im Osten (19,4 Prozent). Nicht leicht zu interpretieren ist, dass die Befragten in Ostdeutschland erheblich öfter (16,5 Prozent) die Wissenschaft für zuständig erklären als diejenigen in Westdeutschland (10,2 Prozent). Auffällig ist ferner, dass die Befragten im Osten insgesamt weniger Instanzen nennen als diejenigen im Osten.

Im Übrigen gibt es bei der Beantwortung dieser Frage einen deutlichen Geschlechtereffekt: Frauen sehen eher Bildungseinrichtungen in der Verantwortung, während Männer Politik und Wissenschaft für zuständig halten: 81,1 Prozent der Frauen, aber nur 65,1 Prozent der Männer nennen die Schule, und 18,0 Prozent der Frauen, aber nur 6,6 Prozent der Männer nennen den Kindergarten; andererseits nennen 45,3 Prozent der Männer, aber nur 32,2 Prozent der Frauen die Politik, und 15,5 Prozent der Männer, aber nur 9,3 Prozent der Frauen nennen die Wissenschaft.

\section{Fremde Sprachen}

Neben den Einstellungen und Meinungen zur eigenen Sprache sind auch die Einstellungen, die man zu anderen Sprachen hat, von Interesse. Dabei gibt es verschiedene Kontexte, in denen man mit je verschiedenen fremden Sprachen in Berührung kommt. Ein zentraler Raum für die Begegnung mit fremden Sprachen ist die Schule, der schulische Fremdsprachenunterricht stellt für viele die einzige institutionalisierte intensivere Auseinandersetzung mit einer anderen Sprache dar. Die dort erworbenen Einstellungen dürften, wie auch das dort erworbene Wissen, je nach Schulbiographie variieren; die Zahl der möglichen Begegnungssprachen ist begrenzt. Ein anderer großer Kontaktbereich sind Urlaubserfahrungen, wo ebenfalls eine starke Prägung der Einstellungen durch außersprachliche Faktoren zu vermuten ist. Ein sehr weites Begegnungsfeld mit Fremdsprachen ist der öffentliche Raum, Werbung, Medien usw., wobei hier klar das Englische dominiert, bzw. genauer: einzelne ursprünglich aus dem Englischen übernommene Einheiten Signale von 
Anderssprachigkeit aussenden. Von anderer Qualität ist schließlich das über Zuwanderer mit einer anderen Muttersprache als Deutsch transportierte Wissen von Mehrsprachigkeit. Eine gewisse öffentliche Sichtbarkeit erreichen hier vor allem die größeren Migrantengruppen, deren Sprachen typischerweise gerade nicht als Schulfremdsprachen fungieren.

In diesem Kapitel werden zunächst sprachliche Fragen, die sich im Zusammenhang mit Zuwanderung stellen, behandelt (Abschnitt 5.1). Anschließend werden die verschiedenen Sympathie- und Antipathiewerte für fremdsprachige Akzente vorgestellt (Abschnitt 5.2). Dem Thema Schulfremdsprachen ist Abschnitt 5.3 gewidmet; abschließend wird nach den Vermutungen und Meinungen zur künftigen Rolle des Englischen als zentralem Kommunikationsmittel in vielen Berufen gefragt (Abschnitt 5.4).

\section{$5.1 \quad$ Zuwanderer}

Der Zuzug von Zuwanderern vor allem im Zusammenhang mit Arbeitsmigration hat den Anteil von Personen mit einer anderen Muttersprache als Deutsch in den Jahrzehnten seit dem Zweiten Weltkrieg spürbar wachsen lassen, in der alten Bundesrepublik wesentlich stärker als in der DDR; die daraus resultierenden Herausforderungen der gesellschaftlichen Integration dürften bis auf weiteres virulent bleiben. Problematisch ist insbesondere, dass die meisten Migranten Sprecher von Sprachen sind, die in der deutschen Mehrheitsgesellschaft mit einem geringeren Prestige ausgestattet sind, so dass die sprachliche Adaptation in aller Regel eine einseitige ist. Umgekehrt gibt es vor allem bei den größeren Migrantengruppen den Effekt, dass sich soziale Räume und Netzwerke bilden, in denen die jeweilige Herkunftssprache dominiert. Die Existenz solcher Bereiche wird von den Befragten überwiegend skeptisch gesehen (46,2 Prozent finden das ,schlecht“ oder ,sehr schlecht"), findet allerdings andererseits auch eine gewisse Zustimmung (rund ein Viertel der Befragten, 26,2 Prozent findet das ,gut" oder ,sehr gut“"). Auch die Verständigung mit Zuwanderern wird vielfach als problematisch empfunden; 45,2 Prozent aller Befragten bewertet sie als ,schwierig“" oder ,sehr schwierig“ (Abbildung 25).

Wie der Vergleich der Mittelwerte veranschaulicht, unterscheiden sich die Befragten in Ost und West hinsichtlich ihrer Bewertung der internen muttersprachlichen Kommunikation von Zuwanderergruppen nicht (Abbildung 26). Allerdings wird die Verständigung mit den Zuwanderern in den westlichen Bundesländern, wo der Ausländeranteil im Schnitt höher ist als im Osten, signifikant kritischer gesehen. 


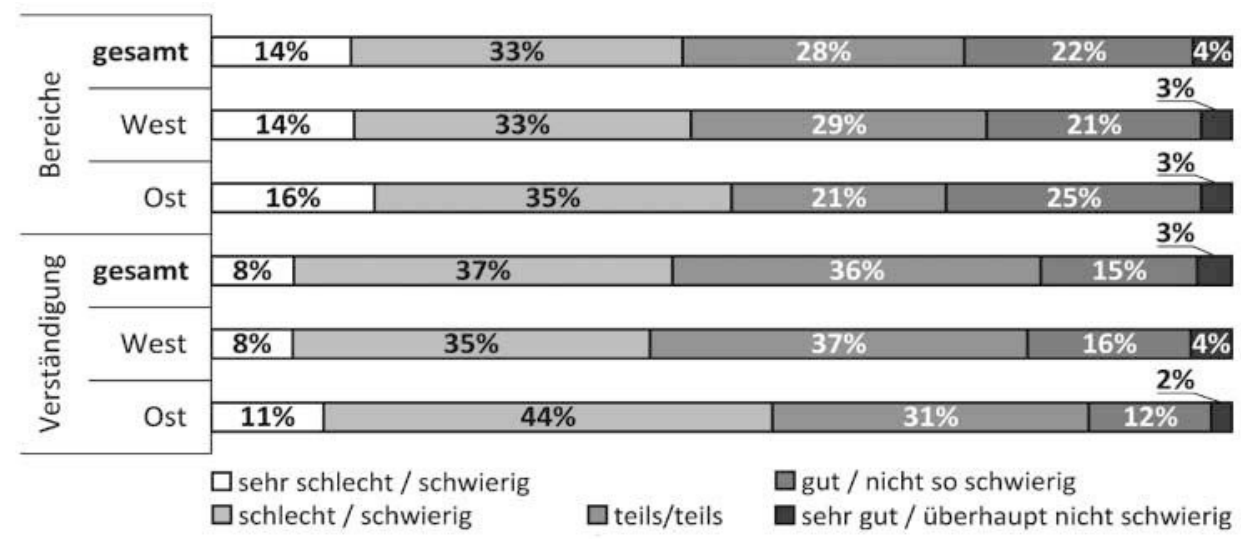

Abbildung 25: Sprachliche Integration von Zuwanderern (nach Herkunft)

Fragen: In einer Reihe von Städten und Gemeinden in Deutschland gibt es Bereiche, wo verschiedene Zuwanderergruppen überwiegend ihre Muttersprache sprechen. Finden Sie das ... (sehr gut, gut, teils/teils, schlecht, sehr schlecht)? und Wie schwierig finden Sie im Allgemeinen die alltägliche Verständigung zwischen deutschsprachigen Personen und anderssprachigen Zuwanderern? (sehr schwierig, schwierig, teils/ teils, nicht so schwierig, überhaupt nicht schwierig)

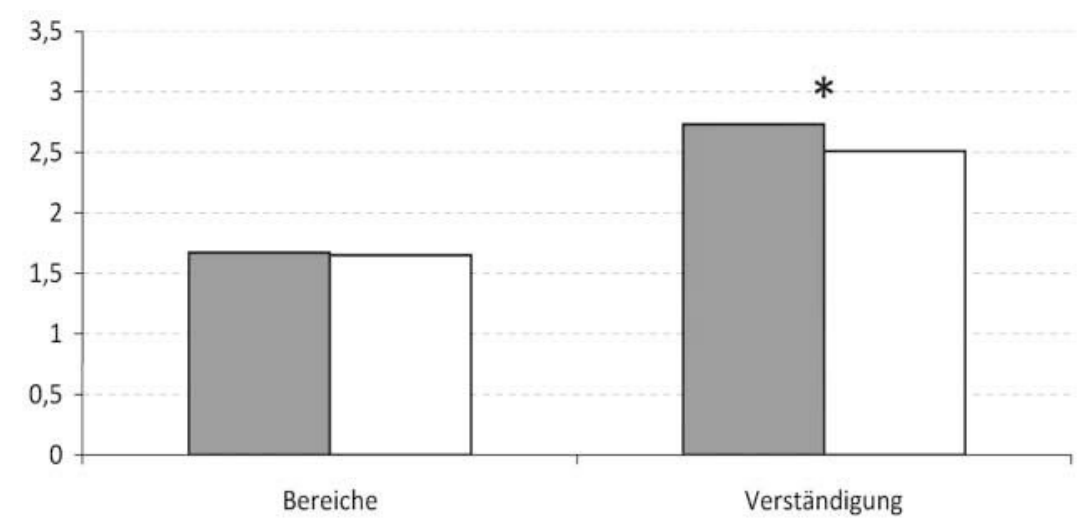

口West प0st

Abbildung 26: Sprachliche Integration von Zuwanderern (nach Herkunft) - Vergleich der Mittelwerte (Fragen wie Abbildung 25)

Auch hier gibt es allerdings wieder eine ganze Reihe von anderen Faktoren, die statistisch eine Rolle spielen. Insbesondere gibt es eine Korrelation mit dem Faktor Bildung, Befragte mit einem höheren Bildungsabschluss schätzen die Kommunikation mit Zuwanderern im Schnitt als weniger schwierig ein. Eine konservative politische Haltung geht wiederum eher mit einer negativen Bewertung der Verständigung mit Zuwanderern einher (vgl. Eichinger et al. 2009, S. 31-34). 


\subsection{Sympathie für fremdsprachige Akzente}

Dass die Sprache Trägerfunktion für Identitäten hat, sieht man besonders deutlich bei den Einstellungen zu fremden Sprachen, die zu hohem Grade immer auch durch Bilder von Ländern und deren Bewohnern determiniert werden. Hier überlagern sich Kollektivstereotype und Individualerfahrungen zu einem gleichwohl schlüssigen Bild. Sympathie hegen die Deutschen mehrheitlich für ihre großen romanischen Nachbarn, Deutsch mit einem französischen Akzent wird mit großem Abstand von 43,5 Prozent der Befragten als sympathisch bezeichnet, an zweiter Stelle wird von immerhin noch 25,2 Prozent der Befragten Deutsch mit einem italienischen Akzent genannt (Abbildung 2721).

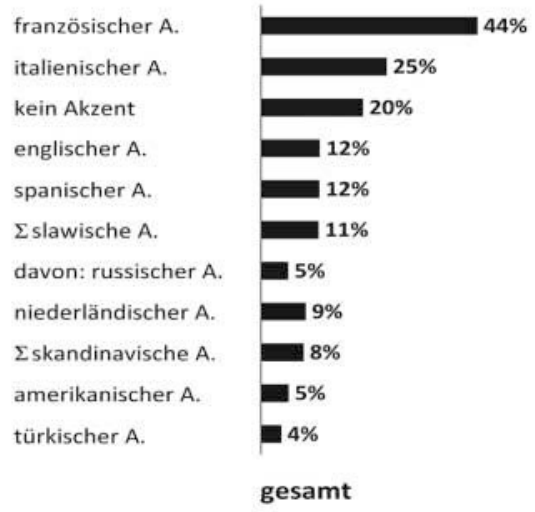
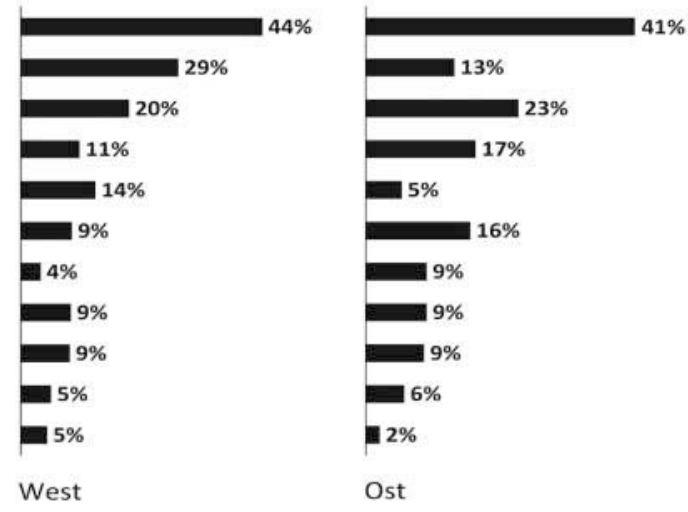

Abbildung 27: Sympathische fremdsprachige Akzente (nach Herkunft)

Frage: Gibt es einen oder mehrere ausländische Akzente, die Sie besonders sympathisch finden? Also gemeint ist nicht die Fremdsprache, sondern die Art und Weise, wie Ausländer Deutsch sprechen. Welche sind das? (Frage nur an Personen mit Deutsch als Muttersprache, Mehrfachnennung möglich)

Der französische Akzent steht als Sympathieträger in allen Gruppen (differenziert nach Alter, Geschlecht, Bildungsabschluss, Herkunft usw.) an erster Stelle, was vor dem Hintergrund der langen politischen und kulturellen Dominanz Frankreichs in Europa, einer langen Tradition des Französischen als Schulfremdsprache in Deutschland, der herausgehobenen politischen Beziehungen beider Länder usw. nicht weiter verwundert. Der Vergleich zwischen Ost- und Westdeutschland zeigt aber auch deutliche Unterschiede. Am auffälligsten ist, dass die beiden anderen großen romanischen Sprachen, Italienisch und Spanisch, im Westen wesentlich häufiger genannt werden als im Osten (einen italienischen Akzent nennen 28,7 Prozent der Westdeutschen und 13,3 Prozent der Ostdeutschen, einen spanischen Akzent 13,5 Prozent der Westdeutschen gegenüber nur 5,3 Prozent der Ostdeutschen). Erst Italien, dann Spanien waren die Haupturlaubsländer der alten Bundesrepublik; Sympathiebezeugungen haben offenbar viel mit Kontakt und Präsenz zu tun.

21 Die Frage war offen formuliert; es waren mehrere Nennungen möglich. Bei den ostdeutschen Befragten waren (wie übrigens auch bei den anderen offenen Fragen) anteilig insgesamt weniger Nennungen zu verzeichnen. - Es werden nur Werte über zwei Prozent abgebildet. Die Kategorie „slawisch“ umfasst die Nennungen für russischen, polnischen, serbischen/kroatischen/serbokroatischen, baltischen, tschechischen und slawischen Akzent. In der Kategorie „skandinavisch“ wurden genannt Dänisch, Schwedisch, Norwegisch und Skandinavisch. 
Deutsch mit einem Akzent einer slawischen Sprache wird von den ostdeutschen Befragten erheblich häufiger genannt als von den westdeutschen (15,7 Prozent im Osten gegenüber 9,2 Prozent im Westen), den höchsten Anteil daran hat Russisch (9,1 Prozent im Osten, nur 3,5 Prozent im Westen). Dass die Sympathieverteilungen aber nicht in erster Linie den politischen Grenzen folgen, sondern tatsächlich Resultate von Kontakten und Nachbarschaften sind, sieht man bei einer noch kleinräumigeren regionalen Analyse. Deutsch mit einem italienischen Akzent nennen im Bundesdurchschnitt 25,2 Prozent der Befragten. In den süddeutschen Bundesländern sind es sogar 35,4 Prozent, in den norddeutschen Ländern folgerichtig nur 21,7 Prozent. ${ }^{22}$ Noch deutlicher ist der Effekt bei den „kleinen“ Nachbarn mit bundesweit gesehen geringerer medialer Präsenz: Deutsch mit einem niederländischen Akzent wird in den nördlichen Bundesländern von 12,2 Prozent der Befragten genannt, in den südlichen nur von 3,8 Prozent. Deutsch mit einem Akzent einer skandinavischen Sprache wird von 11,4 Prozent der Befragten in Norddeutschland, hingegen nur von 3,2 Prozent der Befragten in Süddeutschland genannt.

Ähnlich, wenngleich weniger deutlich divergierend, ist die Situation bei den Antworten auf die Frage nach möglichen unsympathischen Akzenten (Abbildung 28).
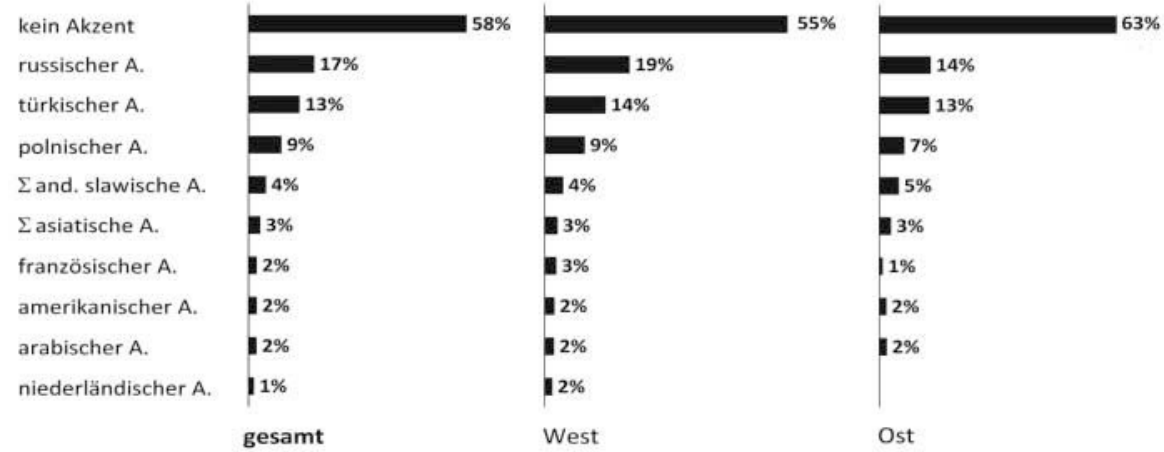

Abbildung 28: Unsympathische fremdsprachige Akzente (nach Herkunft)

Frage: Und gibt es einen oder mehrere ausländische Akzente, die Sie besonders unsympathisch finden? (Frage nur an Personen mit Deutsch als Muttersprache; Mehrfachnennung möglich)

Eine deutliche Mehrheit der Befragten gibt an, dass ihnen kein fremdsprachiger Akzent unsympathisch sei. Es folgen mit großem Abstand der russische, der türkische (der insbesondere in der Altersgruppe der 18-29-Jährigen unbeliebt ist; vgl. Eichinger et al. 2009, S. 31) und der polnische Akzent - und damit die Sprachen der größeren Migrationsminderheiten in Deutschland. Bemerkenswerterweise ist die Ablehnung eines russischen Akzents im Westen erkennbar höher als im Osten (19,2 Prozent gegenüber 13,5 Prozent).

\subsection{Schulfremdsprachen}

Einer derjenigen Bereiche, in denen staatliches Handeln massiv wirksam wird, ist die schulische Sozialisation. Zu erwarten ist daher, dass sich die durch die unterschiedliche Schulpolitik getrennte Bildungsgeschichte der beiden deutschen Staaten nicht nur in den objektiven Daten (beispielsweise darin, welche Fremdsprachenkenntnisse man erworben

22 Norddeutsche Länder: Schleswig-Holstein, Hamburg, Bremen, Niedersachsen, Mecklenburg-Vorpommern; süddeutsche Länder: Bayern, Baden-Württemberg. 
hat) manifestiert, sondern auch in bestimmten Haltungen und Einstellungen niederschlägt - zum Beispiel auch darin, von welchen Fremdsprachen man meint, dass sie in der Schule unterrichtet werden sollten (Abbildung 29).

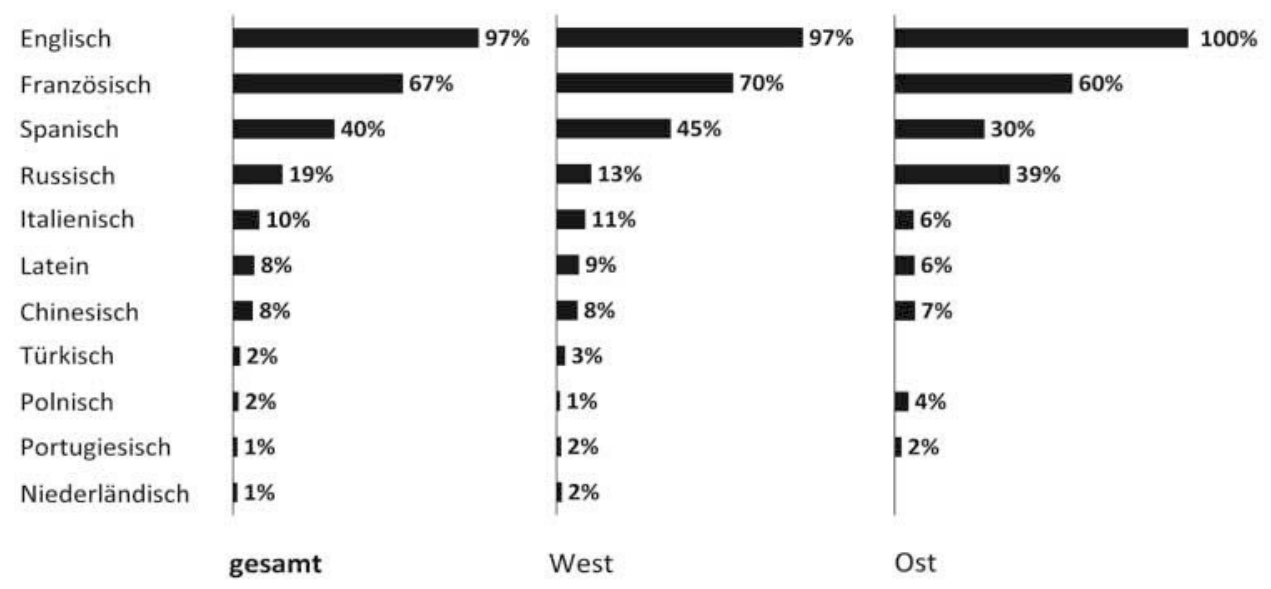

Abbildung 29: Gewünschte Schulfremdsprachen (nach Herkunft)

Frage: Jetzt zur Schule: Welche Fremdsprachen sollten Ihrer Meinung nach in der Schule gelernt werden? (Mehrfachnennung möglich)

In der unbestreitbaren Relevanz des Englischen für die schulische Bildung sind sich die Befragten in Ost und West einig; das Französische als zweite Fremdsprache wäre, ginge es nach dieser Aufstellung, nicht gefährdet, im Westen (69,5 Prozent) noch weniger als im Osten (60,2 Prozent). Der auffälligste Unterschied zwischen Ost und West betrifft wiederum das Russische: Während es im Westen von nur 13,4 Prozent der Befragten genannt wird, wünschen es sich im Osten 38,9 Prozent als Schulfremdsprache und setzen damit Traditionen aus der Vorwendezeit fort. Insgesamt an dritter Stelle mit (erstaunlichen) 40,0 Prozent liegt Spanisch, das im Westen etwa anderthalb mal so oft gewünscht wird wie im Osten (44,8 Prozent gegenüber 30,2 Prozent). Auch Italienisch wird im Westen viel häufiger, nämlich fast doppelt so oft genannt wie im Osten (11,0 Prozent gegenüber 6,1 Prozent) - ist aber trotzdem nicht mehrheitsfähig. Hier dürfte ein gewisser Näheeffekt von Bedeutung sein, ähnlich wie umgekehrt - auf noch niedrigerem Niveau - beim Polnischen, das in Ostdeutschland 4,4 Prozent Nennungen hat, im Westen jedoch nur 1,0 Prozent. Die größte Migrantensprache, Türkisch, spielt in den Wunschlisten weder im Westen noch im Osten eine Rolle.

Russisch war Pflichtfremdsprache in der DDR; die auffällig hohen Werte für das Russische im Osten sind als ein Erbe des DDR-Fremdsprachenunterrichts zu werten. Wie eine Untergliederung nach Altersgruppen zeigt, beschränkt sich die Wertschätzung des Russischen als Schulfremdsprache jedoch nicht auf die Altersgruppen, die den entsprechenden Unterricht erhalten haben (Tabelle 4). 


\begin{tabular}{lcccccc}
\hline & West & \multicolumn{5}{c}{ Ost } \\
\hline & $18-29$ & $30-59$ & $60+$ & $18-29$ & $30-59$ & $60+$ \\
\hline Englisch & 95,2 & 97,8 & 96,9 & 100,0 & 99,4 & 99,6 \\
Französisch & 69,3 & 66,7 & 74,5 & 63,4 & 62,6 & 55,4 \\
Spanisch & 50,7 & 46,1 & 39,3 & 35,0 & 36,2 & 19,4 \\
Russisch & 10,1 & 13,4 & 15,3 & 32,2 & 38,1 & 42,9 \\
Italienisch & 7,8 & 9,8 & 14,6 & 8,2 & 6,0 & 5,2 \\
Latein & 13,2 & 7,5 & 7,8 & 8,9 & 5,1 & 6,9 \\
Chinesisch & 7,7 & 8,8 & 6,5 & 6,5 & 4,4 & 9,4 \\
\hline
\end{tabular}

Tabelle 4: Gewünschte Schulfremdsprachen, nach Herkunft und Alter (Frage wie Abbildung 29, Angaben in Prozent)

Hier sieht man, dass auch ein gutes Drittel (32,2 Prozent) der jüngsten Altersgruppe, der Gruppe der zum Befragungszeitpunkt (Herbst 2008) 18-29-Jährigen, d.h. die Geburtsjahrgänge 1979 bis 1990, die beim Mauerfall höchstens zehn Jahre alt waren, das Russische nennt. Das ist zwar weniger als in den beiden älteren Altersgruppen, doch das stimmt auch für den Westen. Im Ost-West-Vergleich der jeweiligen Alterskohorten liegen die ostdeutschen Befragten in allen Gruppen etwa um den Faktor 3 über den entsprechenden westdeutschen Gruppen.

Ein deutlicher Alterseffekt, im Westen wie im Osten, zeigt sich übrigens auch beim Latein, das in der jüngsten Altersgruppe wesentlich an Beliebtheit gewinnt.

Dass die gewünschten Fremdsprachen mit den jeweiligen eigenen Lernbiographien verknüpft sind, ist aus den Antworten auf die Frage nach den gelernten Fremdsprachen ablesbar (Tabelle 5).

\begin{tabular}{lcccc}
\hline & West & Rang & Ost & Rang \\
\hline Englisch & 78,3 & 1 & 62,3 & 2 \\
Französisch & 31,4 & 2 & 11,8 & 3 \\
Russisch & 2,6 & & 69,6 & 1 \\
$\begin{array}{l}\text { Nein, kann } \\
\text { keine weiteren }\end{array}$ & 19,1 & 3 & 10,6 & 4 \\
$\begin{array}{l}\text { Sprachen } \\
\text { Italienisch }\end{array}$ & 5,3 & & 0,9 & \\
Latein & 9,1 & 4 & 4,9 & \\
Niederländisch & 1,7 & & 0,2 & \\
Spanisch & 8,9 & & 3,2 & \\
\hline
\end{tabular}

Tabelle 5: Gelernte Fremdsprachen (nach Herkunft)

Frage: Haben Sie eine oder mehrere Fremdsprachen gelernt? Wenn ja, welche?

Auch hier macht wieder Russisch den Unterschied; die Werte im Westen und im Osten unterscheiden sich so dramatisch, dass eine Tabelle, die die bundesweit gemittelten Zahlen wiedergibt, unsinnig wäre.

Auch hier ist eine Aufschlüsselung nach Altersgruppen aufschlussreich (Tabelle 6). 


\begin{tabular}{lllllll}
\hline & West & \multicolumn{5}{c}{ Ost } \\
\hline & $18-29$ & $30-59$ & $60+$ & $18-29$ & $30-59$ & $60+$ \\
Englisch & 100,0 & 92,3 & 45,3 & 94,5 & 70,1 & 36,5 \\
Französisch & 45,3 & 34,0 & 21,4 & 41,4 & 6,9 & 5,0 \\
$\begin{array}{l}\text { Russisch } \\
\text { Nein, kann }\end{array}$ & 4,3 & 2,0 & 2,9 & 31,2 & 85,6 & 64,7 \\
$\begin{array}{l}\text { keine weiteren } \\
\text { Sprachen }\end{array}$ & & 6,6 & 48,1 & 1,9 & 5,9 & 21,4 \\
Italienisch & 5,6 & 6,3 & 3,6 & 3,9 & 0,5 & 0,2 \\
Latein & 13,9 & 9,5 & 6,7 & 15,4 & 0,9 & 5,8 \\
Niederländisch & 4,8 & 1,5 & 0,7 & & 0,2 & 0,2 \\
Spanisch & 23,2 & 8,1 & 4,5 & 9,5 & 2,3 & 1,5 \\
\hline
\end{tabular}

Tabelle 6: Gelernte Fremdsprachen, nach Herkunft und Alter (Frage wie Tabelle 5, Angaben in Prozent)

Vor allem ist hier die inzwischen erreichte zuverlässige Etablierung des Englischen als obligatorischer Schulfremdsprache ablesbar. Russisch ist offenbar im Osten noch immer stabil verankert; Latein wird dort seit der Wende wieder verstärkt unterrichtet.

\subsection{Die künftige Rolle des Englischen im Beruf}

Die hohe öffentliche Sichtbarkeit von Sprachformen angelsächsischer Provenienz wird zwar vielfach als Bedrohung empfunden und befeuert einen bestimmten sprachkritischen Diskurs (vgl. dazu z.B. Spitzmüller 2008), braucht aber für sich genommen noch keine systematische Gefahr für das Deutsche darzustellen. Das eigentliche Problem, das aus der Dominanz der englischen Sprache erwächst, könnte vielmehr im allmählichen Domänenverlust des Deutschen liegen, wie er in einigen international kontextualisierten Kommunikationsbereichen (etwa der Luftfahrt), in bestimmten wirtschaftlichen Segmenten sowie in einigen Wissenschaftsdisziplinen bereits vollzogen ist. Ein Szenario, nach dem das Deutsche nur noch für die alltägliche Kommunikation gebraucht wird, sozusagen mit dem Status von Dialekten, in professionellen Zusammenhängen aber nur noch Englisch gesprochen würde, wird von der Mehrheit der Befragten für unwahrscheinlich gehalten (aber immerhin mehr als zwei Fünftel nehmen an, dass es so kommt); zugleich wird es auch nicht gewünscht (Abbildung 30). 


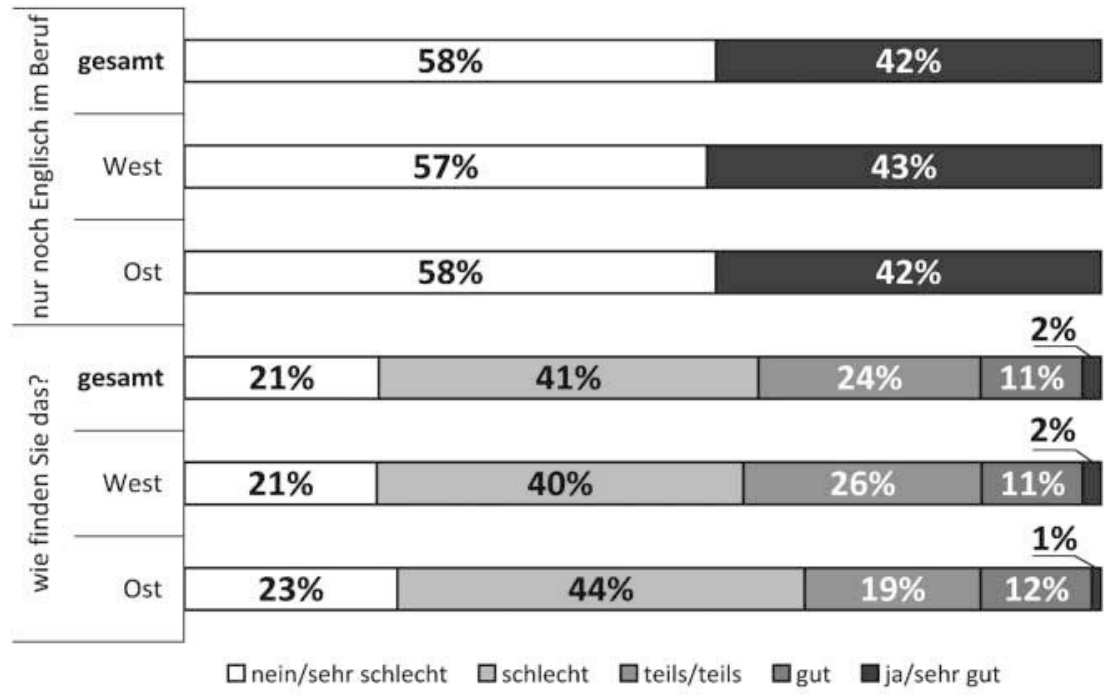

Abbildung 30: Englisch im Beruf (nach Herkunft)

Fragen: Und glauben Sie, dass es in einigen Jahrzehnten dazu kommen wird, dass in Deutschland im Beruf ... überwiegend nur noch Englisch gesprochen wird, oder glauben Sie das nicht? (ja, nein, weiß nicht/keine Angabe) und Wenn in einigen Jahrzehnten in Deutschland im Beruf überwiegend nur noch Englisch gesprochen werden würde, fänden Sie das ... (sehr gut, gut, teils/teils, schlecht, sehr schlecht, weiß nicht/keine Angabe)?

Bei der Frage nach der Eintretenswahrscheinlichkeit des Szenarios unterscheiden sich die Befragten in Ost und West nicht voneinander. Bemerkenswert gering sind allerdings auch die Unterschiede bei der Bewertung des Szenarios. Zwar fällt die Ablehnung im Osten erkennbar höher aus als im Westen (,sehr schlecht“ oder „schlecht“ antworten im Osten 67,2 Prozent, im Westen 60,8 Prozent) - angesichts der Tatsache, dass ein flächendeckender Englischunterricht in den neuen Bundesländern erst die Schülergenerationen seit der Wende erreicht, hätte man aber mit noch größeren Divergenzen rechnen können.

Aufschlussreich ist in diesem Zusammenhang eine Aufschlüsselung der Daten nach Altersgruppen und nach Herkunft (Abbildung 31).

Hier sieht man, dass der Alterseffekt den Ost-West-Effekt deutlich dominiert. Die auffälligste Ost-West-Differenz gibt es in der Gruppe der 18-29-Jährigen. Hier zeigen sich die Befragten im Westen deutlich weniger ablehnend als im Osten (,sehr schlecht"“/,schlecht“: 45,8 Prozent im Westen gegenüber 55,7 Prozent im Osten). 


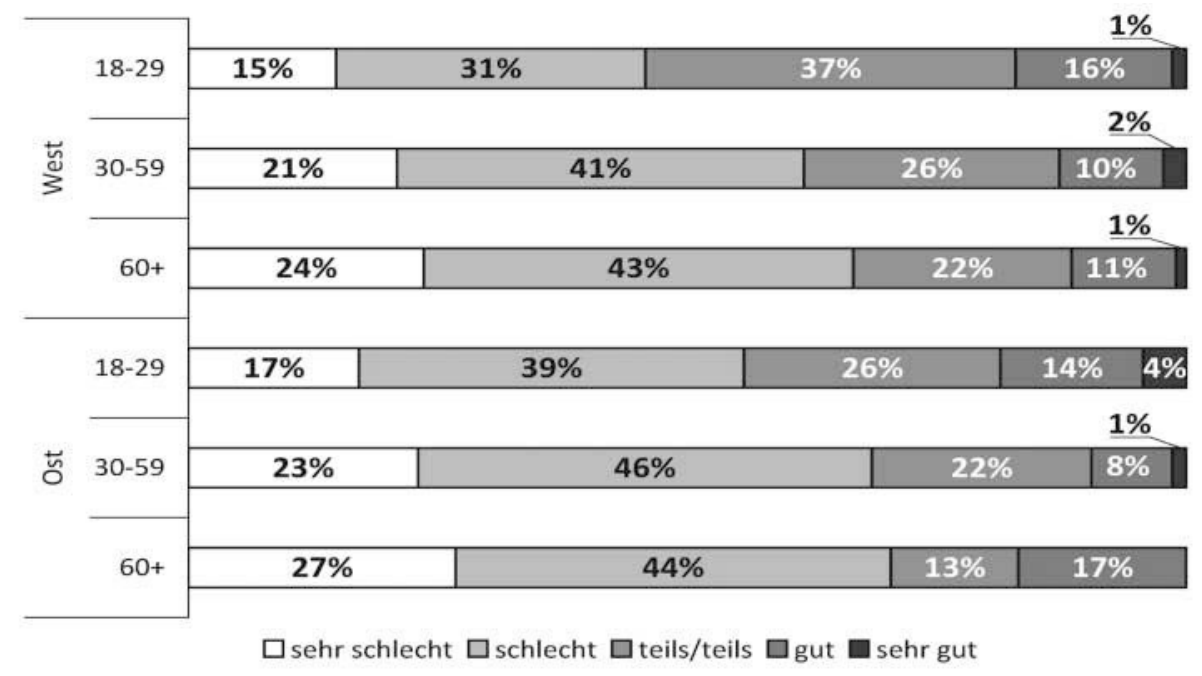

Abbildung 31: Englisch im Beruf, nach Herkunft und Alter (Fragen wie Abbildung 30)

\section{Regionale Varietäten}

Was oben in Kapitel 2 im Zusammenhang mit den sprachlichen Unterschieden zwischen Nord und Süd bzw. Ost und West schon angedeutet wurde, soll hier noch einmal vertieft werden. Das Deutsche verfügt über eine Vielzahl regionaler Varietäten, die sich in mehrfacher Hinsicht unterscheiden, in ihren Sprecherzahlen, in ihrer Verankerung im Diasystem, in ihrem Abstand vom Standard, in ihrer medialen Präsenz und nicht zuletzt in ihrem - wiederum regional unterschiedlichen - Prestige und in dem Wissen, das die Sprecher einzelner Varietäten über andere Varietäten haben. Besonders prominent sind in dieser Hinsicht Bairisch und Sächsisch. In allen Untersuchungen, die die Sympathiewerte der verschiedenen deutschen Dialekte zum Gegenstand haben, belegen Bairisch und Sächsisch herausgehobene Positionen. Auf die Frage nach sympathischen Dialekten wurde das Bairische in dieser Umfrage von 20,2 Prozent der Befragten genannt und belegt damit hinter Norddeutsch, das von 24,2 Prozent der Befragten genannt wurde, den zweiten Platz. ${ }^{23}$ Auf die Frage nach unsympathischen Dialekten wurde an erster Stelle, von 29,6 Prozent der Befragten, Sächsisch genannt; 27,9 Prozent der Befragten geben an, ihnen sei kein Dialekt unsympathisch; an dritter Stelle, mit 13,5 Prozent, folgt wiederum das Bairische (vgl. Eichinger et al. 2009, S. 20-21). Natürlich mischen sich auch hier Bilder von der Sprechweise mit den Bildern von den zugehörigen Sprechern; Bairisch wird mit Bayern identifiziert und umgekehrt Bayern mit Bairisch, analog Sächsisch mit Sachsen und umgekehrt.

23 Die Frage war offen formuliert, d.h. es waren keine Antwortkategorien vorgegeben. Entsprechend unübersichtlich und von unterschiedlichem Präzisionsgrad waren die gegebenen Antworten; die Kategorie „Norddeutsch“ fasst alle Meldungen, die in irgendeiner Weise auf norddeutsche Regionalität referieren, zusammen, obgleich im Einzelfall unklar bleiben muss, ob niederdeutsche Dialekte oder Varianten norddeutscher Umgangssprachen gemeint sind. 


\subsection{Bayern und Sachsen}

Analog zu den Fragen, mit denen oben die Einstellungen zum „typischen Deutschen“ ermittelt wurden (vgl. die Abbildungen 16 und 17 in Abschnitt 3.4), wurde mit denselben semantischen Differentialen (freundlich, gebildet und temperamentvoll) jeweils die Hälfte der Stichprobe einerseits nach dem typischen Bayern und andererseits nach dem typischen Sachsen gefragt. Wie man sieht, ist die Bewertung des typischen Bayern insgesamt sehr positiv, und die ost- und westdeutschen Befragten liegen wiederum recht nah beieinander (Abbildung 32).

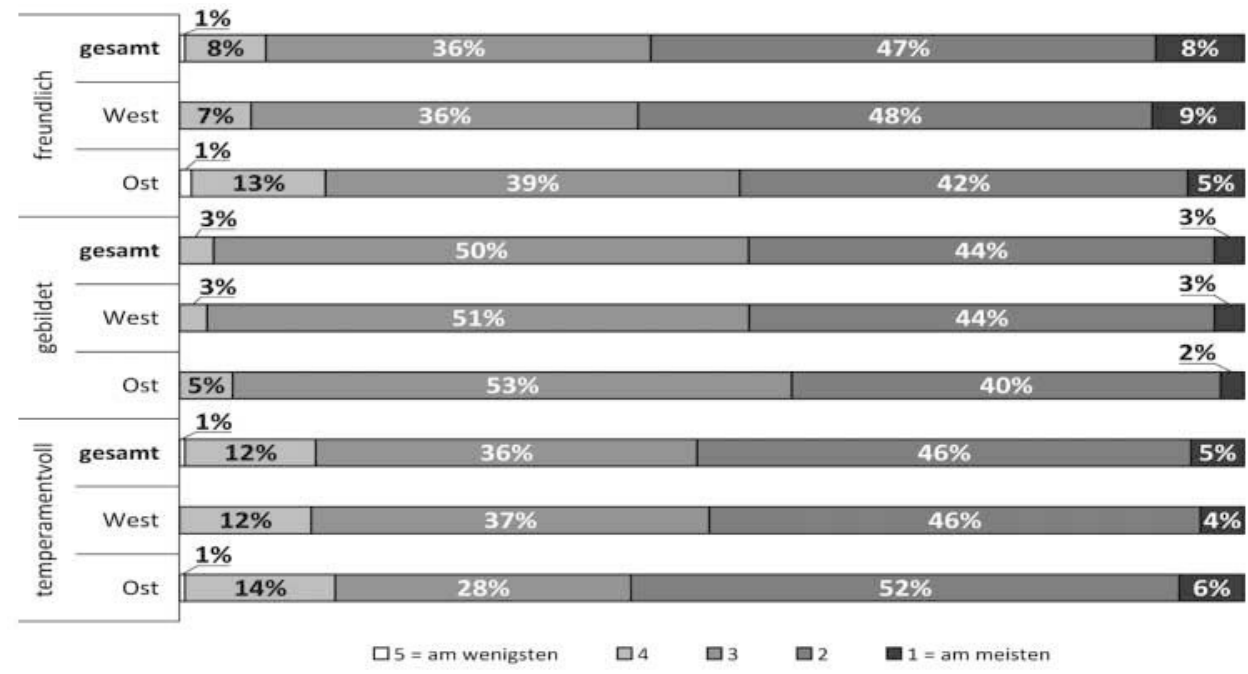

Abbildung 32: Der typische Bayer (nach Herkunft)

Fragen: Und jetzt nach dem Dialekt zu den Menschen: Was meinen Sie zu folgenden Eigenschaften: Ist der typische Bayer Ihrer Meinung nach ... bzw. Ist die typische Bayerin Ihrer Meinung nach ... a) sehr freundlich, freundlich, teils/teils, unfreundlich, sehr unfreundlich, weiß nicht/keine Angabe? und b) sehr gebildet, gebildet, teils/teils, ungebildet, sehr ungebildet, weiß nicht/keine Angabe? und c) sehr temperamentvoll, temperamentvoll, teils/teils, ruhig, sehr ruhig, weiß nicht/keine Angabe? (Stichprobe geteilt)

Dezidiert negative Urteile gibt es fast gar nicht. Einen leichten West-Ost-Unterschied gibt es beim Merkmal temperamentvoll (ähnlich wie oben beim typischen Deutschen), wo der typische Bayer bei den ostdeutschen Befragten leicht höhere Werte erzielt als bei den Westdeutschen; diese Differenz wird jedoch, wie der Vergleich der Mittelwerte zeigt, statistisch nicht signifikant (Abbildung 33). 


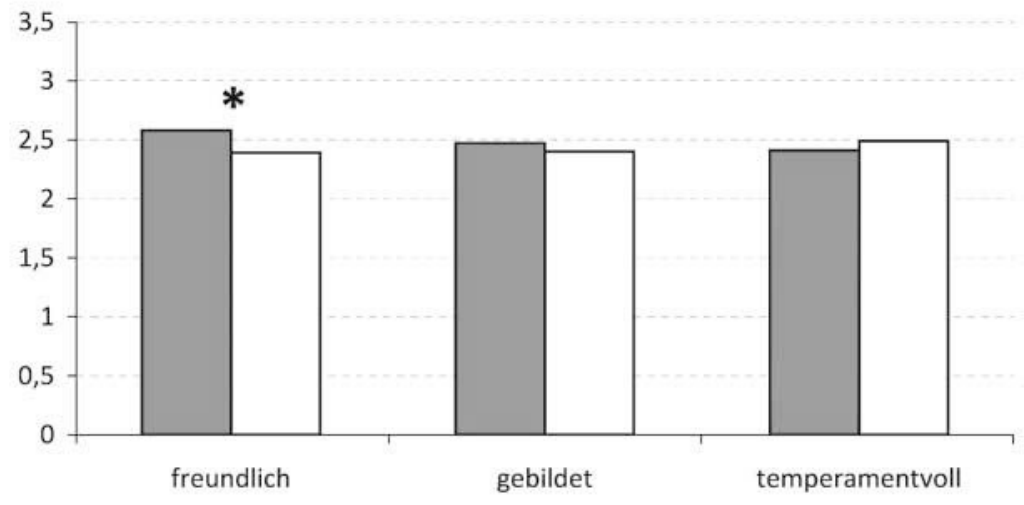

口West $\quad$ 口ost

Abbildung 33: Der typische Bayer (nach Herkunft) - Vergleich der Mittelwerte (Fragen wie Abbildung 32)

Einen statistisch signifikanten Unterschied gibt es hingegen beim Merkmal freundlich, wo die Westdeutschen den typischen Bayern im Schnitt als freundlicher bewerten als die Ostdeutschen; dies ist zumindest teilweise ein Effekt der positiven Selbstbewertung durch die - zahlenmäßig große Gruppe - der bayerischen Befragten.

Erheblich größer sind die Unterschiede zwischen West und Ost in der Bewertung des typischen Sachsen (Abbildung 34).

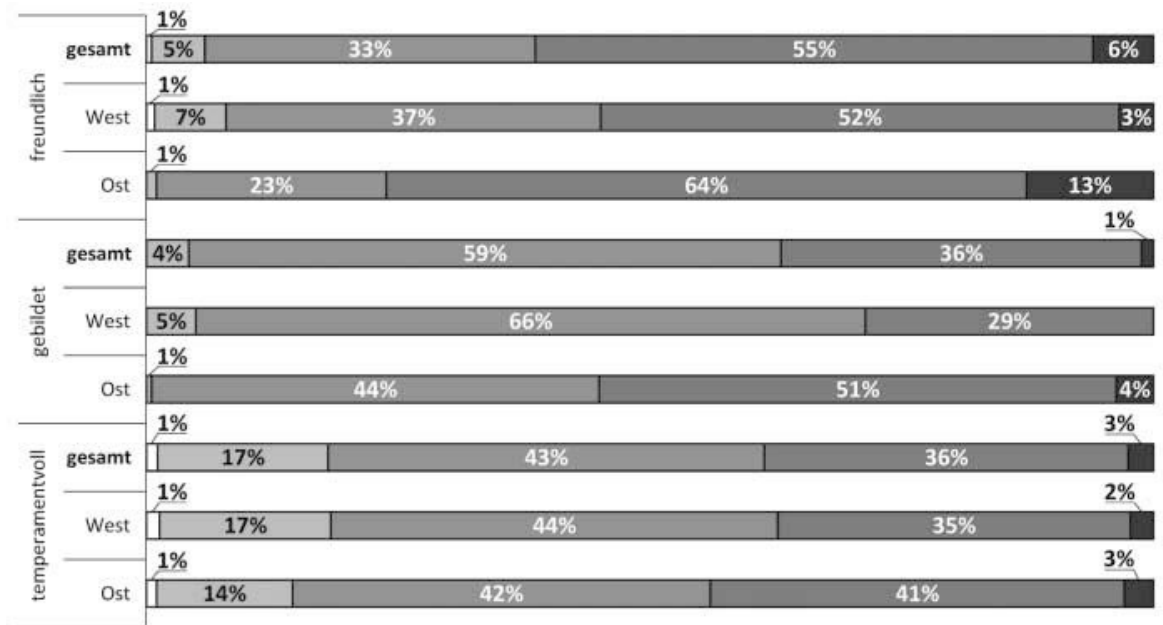

$\square 5=$ am wenigsten $\square 4 \quad \square 3 \quad \square_{2} \quad \mathbf{Q}_{1}=$ am meisten

Abbildung 34: Der typische Sachse (nach Herkunft)

Fragen: Und jetzt nach dem Dialekt zu den Menschen: Was meinen Sie zu folgenden Eigenschaften: Ist der typische Sachse Ihrer Meinung nach ... bzw. Ist die typische Sächsin Ihrer Meinung nach ... a) sehr freundlich, freundlich, teils/teils, unfreundlich, sehr unfreundlich, weiß nicht/keine Angabe? und b) sehr gebildet, gebildet, teils/teils, ungebildet, sehr ungebildet, weiß nicht/keine Angabe und c) sehr temperamentvoll, temperamentvoll, teils/teils, ruhig, sehr ruhig, weiß nicht/keine Angabe? (Stichprobe geteilt) 
Hier sind die Werte bei den ostdeutschen Befragten durchweg höher als bei den westdeutschen, beim Merkmal temperamentvoll geringfügig, beim Merkmal gebildet hingegen dramatisch (für „gebildet“ halten den typischen Sachsen 51,3 Prozent der Ostdeutschen, aber nur 28,5 Prozent der Westdeutschen), desgleichen beim Merkmal freundlich (76,2 Prozent der Ostdeutschen, aber nur 54,9 Prozent der Westdeutschen halten den typischen Sachsen für „freundlich“ oder „sehr freundlich“). Die Abstände werden auch beim Vergleich der Mittelwerte sehr deutlich (Abbildung 35).

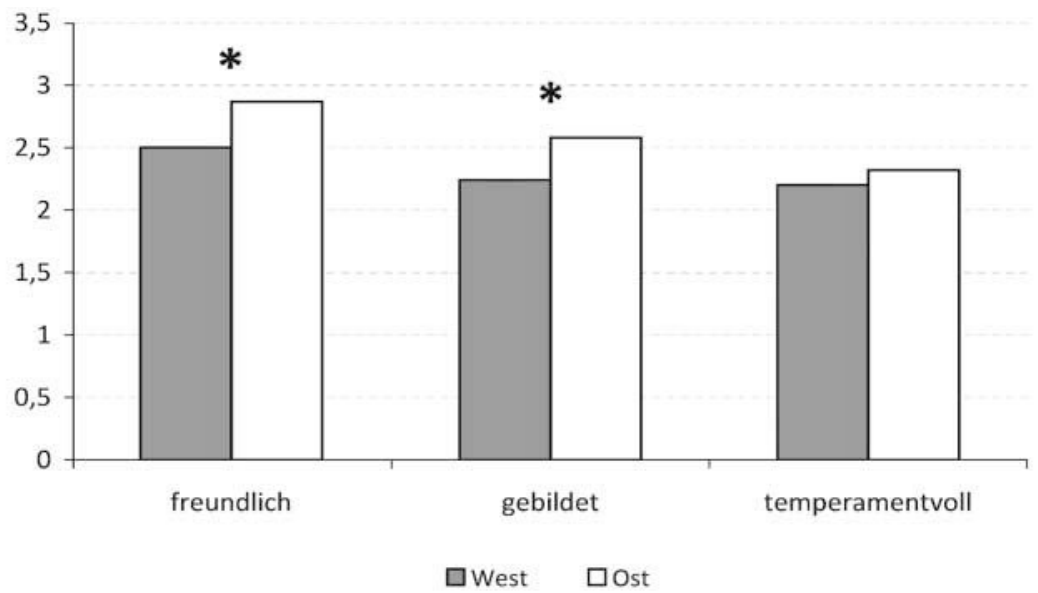

Abbildung 35: Der typische Sachse (nach Herkunft) - Vergleich der Mittelwerte (Fragen wie Abbildung 34)

Offenbar dominiert im Westen nach wie vor ein Negativklischee, das Sachsen in nachteiliger Weise mit der DDR identifiziert, während es möglicherweise gerade eine Ostidentität ist, die den Sachsen bei vielen ostdeutschen Befragten zu einer positiven Wahrnehmung verhilft.

\subsection{Bairisch und Sächsisch}

Analog zu den Fragen zur deutschen Standardsprache (vgl. oben Abschnitt 3.2) sollten auch die Einstellungen der Befragten zu Bairisch und Sächsisch über die mit diesen Dialekten verbundenen Eigenschaftszuschreibungen ermittelt werden. Erfragt wurden auch hier die Faktoren Wert (über die Items schön und anziehend), Struktur (über die Items logisch und einfach) und Klang (über die Items weich und melodisch). Wenig überraschend unterscheiden sich die Befragten zentral in der Selbstbewertung. So wird Bairisch in Bayern und Sächsisch in Sachsen jeweils positiver bewertet als im Bundesdurchschnitt (vgl. Eichinger et al. 2009, S. 22-24). Doch auch im Ost-West-Vergleich gibt es auffällige Differenzen. In diesem Zusammenhang seien exemplarisch die Ergebnisse zu den Items schön und weich vorgestellt.

Die Tatsache, dass bei der Frage nach der Sympathie Bairisch im Bundesdurchschnitt sehr hohe, Sächsisch hingegen regelmäßig sehr niedrige Werte erhält, dürfte sich auch in den Werten der Eigenschaftszuschreibungen niederschlagen. In der Tat zeigt sich diese Polarisierung beim Faktor Wert (über das Item schön) sehr deutlich (Abbildung 36). 


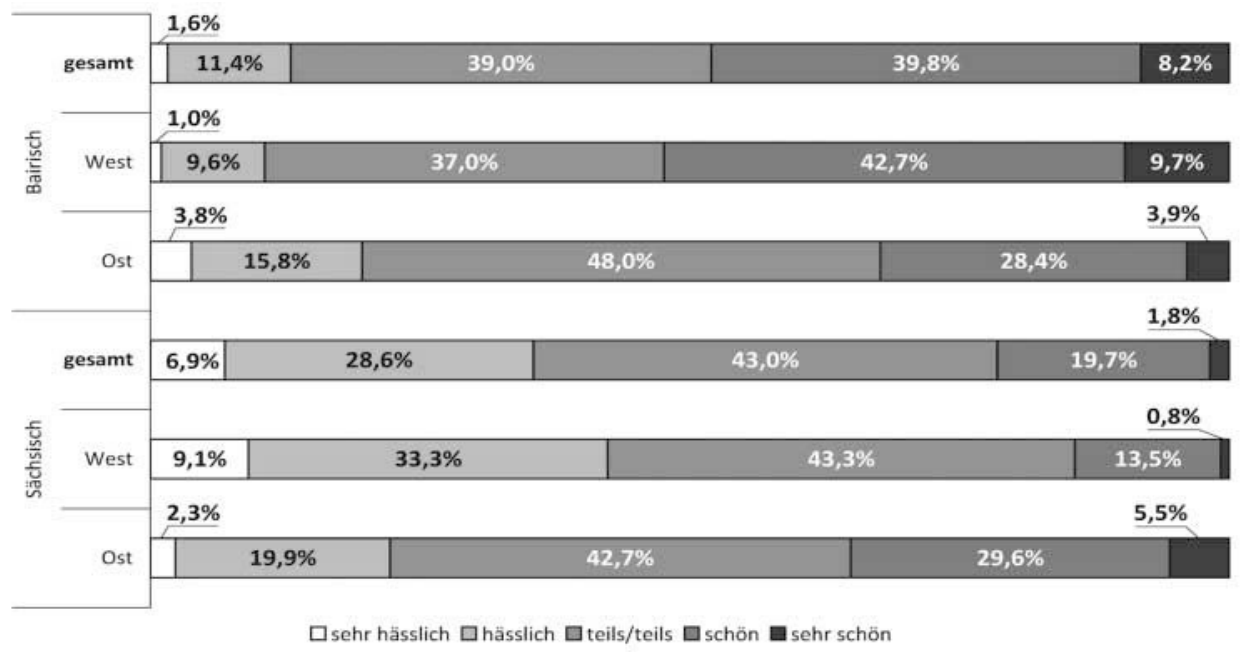

Abbildung 36: Eigenschaftszuschreibungen: „schön“ für Bairisch und Sächsisch

Frage: Es gibt ja sehr viele verschiedene deutsche Dialekte oder Arten von Platt. Im Folgenden soll es um Ihre Meinung zum Bairischen gehen. Ist Bairisch Ihrer Meinung nach ... bzw. Im Folgenden soll es um Ihre Meinung zum Sächsischen gehen. Ist Sächsisch Ihrer Meinung nach ... sehr schön, schön, teils/teils, hässlich, sehr hässlich, weiß nicht/keine Angabe? (Stichprobe geteilt)

Hier sieht man, dass zum einen wie erwartet Bairisch insgesamt wesentlich positiver bewertet wird (48,0 Prozent aller Befragten finden Bairisch „schön“ oder „sehr schön“, aber nur 21,5 Prozent aller Befragten finden Sächsisch „schön“ oder „sehr schön“). Man sieht zum anderen aber auch einen deutlichen Ost-West-Effekt, der mit den Ergebnissen aus Abschnitt 6.1 korrespondiert: Bairisch wird von den Westdeutschen in signifikant höherem Maße für schön gehalten als von den Ostdeutschen; umgekehrt wird aber auch Sächsisch (wenngleich auf insgesamt niedrigerem Niveau) von den Ostdeutschen in signifikanter Weise eher für schön gehalten als von den Westdeutschen.

Ähnlich stellt sich die Situation für das Merkmal weich dar (Abbildung 37). Hier liegen, was das Bairische betrifft, die Befragten in Ost und West einigermaßen nah beieinander. Das Bairische wird zwar von den Westdeutschen im Schnitt etwas eher als weich beurteilt als von den Ostdeutschen, aber der Unterschied wird statistisch nicht signifikant. Sehr wohl signifikant ist die Differenz jedoch in Bezug aufs Sächsische: 52,1 Prozent der ostdeutschen Befragten, aber nur 25,8 Prozent der westdeutschen Befragten bezeichnen Sächsisch als ,weich“ oder ,sehr weich“. 


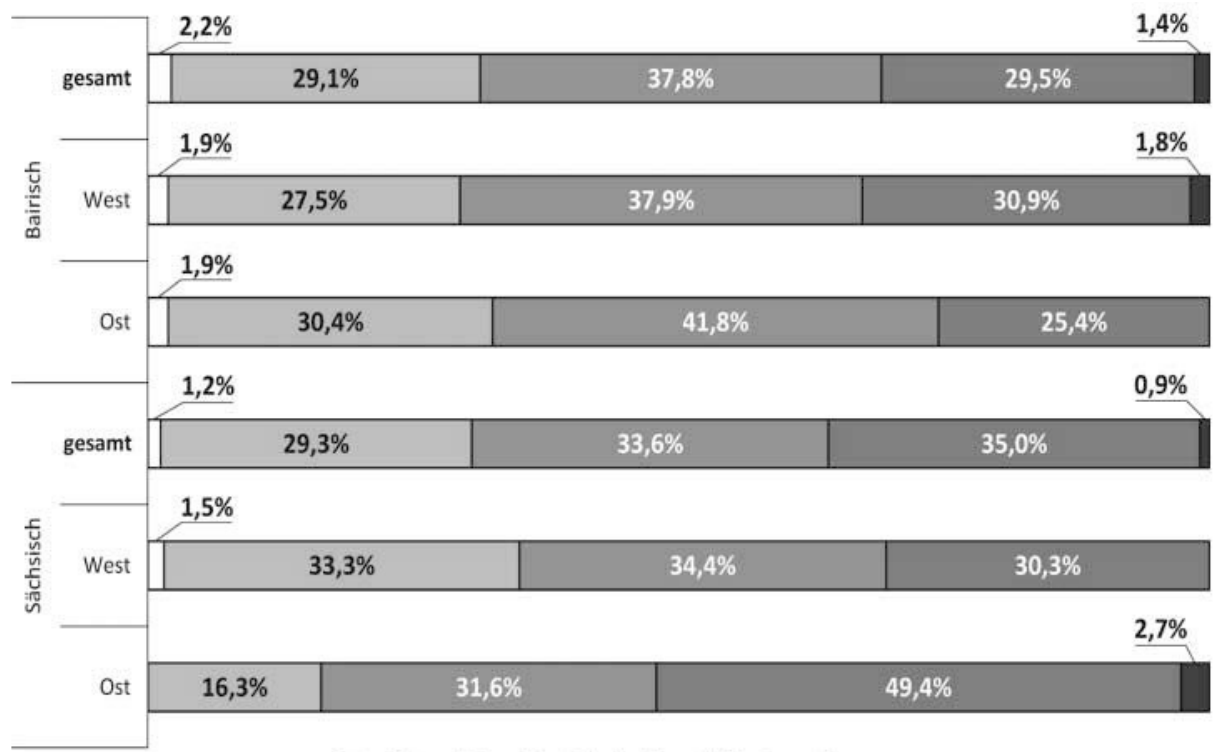

$\square$ sehr hart $\square$ hart $\square$ teils/teils $\square$ weich $\square$ sehr weich

Abbildung 37: Eigenschaftszuschreibungen: „weich“ für Bairisch und Sächsisch

Frage: Es gibt ja sehr viele verschiedene deutsche Dialekte oder Arten von Platt. Im Folgenden soll es um Ihre Meinung zum Bairischen gehen. Ist Bairisch Ihrer Meinung nach ... bzw. Im Folgenden soll es um Ihre Meinung zum Sächsischen gehen. Ist Sächsisch Ihrer Meinung nach ... sehr weich, weich, teils/teils, hart, sehr hart, weiß nicht/keine Angabe? (Stichprobe geteilt)

Diese unterschiedlichen Bewertungen lassen sich auch aus dem Vergleich der Mittelwerte ablesen (Abbildung 38).

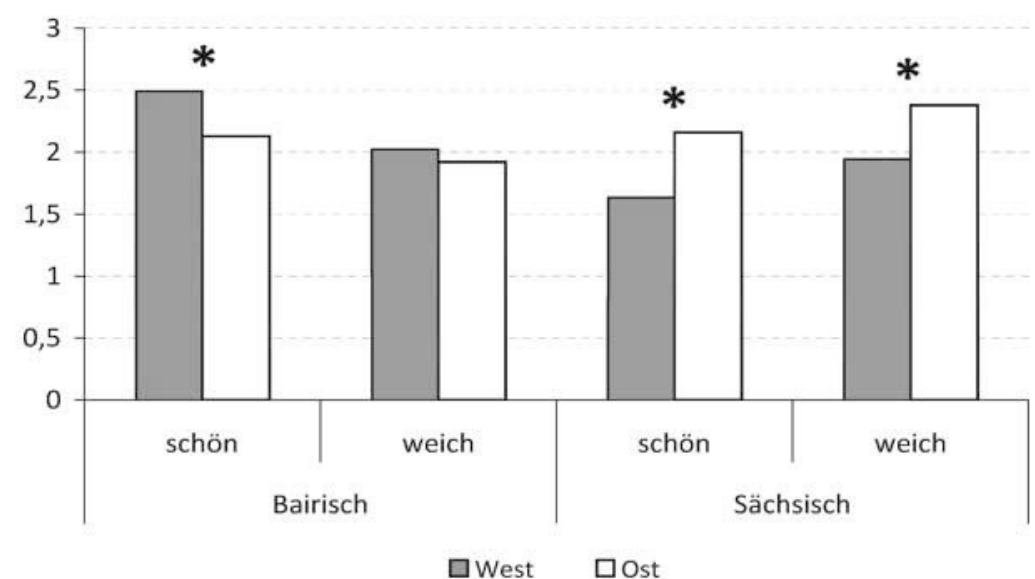

Abbildung 38: Eigenschaftszuschreibungen für Bairisch und Sächsisch - Vergleich der Mittelwerte (Fragen wie Abbildungen 36 und 37) 
Auffällig sind insbesondere die sehr divergenten Einschätzungen in Bezug auf das Sächsische; Sächsisch - und die Sachsen - werden offenbar im Ostteil Deutschlands insgesamt viel positiver gesehen als im Westteil. Inwieweit sich daraus eine Interpretation ableiten lässt, die den Sachsen eine Rolle als prominenten Träger einer Ost-Identität und damit, im positiven wie im negativen Sinne, als prototypische Ostdeutsche zuschreibt, ist nur aufgrund dieser Daten nicht abschließend zu beantworten.

\section{7. $\quad$ Eine Frage der Zeit}

Sind sich die Deutschen in Ost und West, zwanzig Jahre nach der Fall der Mauer, nun fremd? Hellmann, der mit guten Argumenten ,die sprachliche Vereinigung zwischen Ost und West im Wesentlichen für abgeschlossen“ (Hellmann 2004, S. 17) erklärt, sieht auf jeden Fall kein Sprachproblem:

Missverstehen, Kommunikationsabbrüche zwischen Ost- und Westdeutschen haben also ihre Ursache woanders: in unterschiedlichen Mentalitäten, Einstellungen, Erfahrungshorizonten, kommunikativen Regeln (...), in gegenseitigen Vorbehalten, unterschiedlichen Fremd- und Selbstbildern, Schuldzuweisungen u. Ä. (Hellmann 2004, S. 18)

Nach den hier referierten Ergebnissen kann man sogar noch einen Schritt weiter gehen: Zumindest was die Sprache betrifft, sind die Einstellungen so unterschiedlich nicht. Die sprachliche Welt sehen die Deutschen in Ost und West, schaut man aus einigem Abstand, mit sehr ähnlichen Augen. Das gilt auf jeden Fall für die allgemeinen Spracheinstellungen, für das Interesse an Sprache generell, für die Meinungen und emotionalen Haltungen zum Deutschen. Es gilt auch, wenngleich in etwas modifizierter Weise, für die Bewertungen des Sprachgebrauchs, für die Meinungen zur Entwicklung des Deutschen und zu den sich daraus ergebenden sprachpolitischen Implikationen. Hier zeigen sich die Befragten in Ostdeutschland zwar insgesamt etwas skeptischer, etwas konservativer; zugleich wird aber deutlich, dass die Beantwortung der entsprechenden Fragen in entscheidenderem Maße mit anderen Faktoren korreliert als mit dem der Herkunft. Bei einigen Fragekomplexen treten auch größere Unterschiede zwischen Ost und West zutage, die sich teilweise auf die unterschiedliche Regionalgeschichte, auf die Sozialisation in verschiedenen Systemen zurückführen lassen. Das ist etwa sehr deutlich der Fall bei den Fragen zu den gewünschten Schulfremdsprachen. Bisweilen liegen den scheinbaren Ost-West-Gegensätzen jedoch auch noch tiefere, regionale Differenzen zugrunde, die sich wiederum als gewöhnliche Variation im Raum beschreiben lassen, etwa bei der Frage nach der Sympathie für fremdsprachige Akzente, wo Nachbarschaftseffekte eine ganz entscheidende Rolle zu spielen scheinen.

Gleichwohl gibt es das fest verankerte Wissen um die - im doppelten Wortsinne - geteilte Geschichte: die gemeinsame und die getrennte Geschichte, und um die getrennte Alltagsgeschichte, die für diejenigen, die bewusst an ihr Teil hatten, Identitätsbaustein bleibt. Dass das bleibt und nicht verschwindet, wird eindrücklich von Christoph Dieckmann (Jahrgang 1956) beschrieben, der stellvertretend für viele seiner Generation zitiert sei:

Auch die Zeiten verschwimmen, hüben und drüben des Grabens der Geschichte. Dessen Ufer verwandeln sich einander an. Aber immer weiß ich, was vor und was nach der Wende geschah. (...) Ich weiß nicht, was kommt, nur daß Ost und West nicht nachträglich zusammenwachsen können - nicht ihre 40 Jahre Unterschiedsgeschichte. Sie wirkt fort, solange wir leben, denn wir erinnern uns verschieden - Ost und West und jeder für sich. Und dann gibt es noch hundert Differenzen zwischen Klein- und Großgeschichte, zwischen Epochenurteil und privatem Erinnern. (Dieckmann 2009, S. 25-26) 
Und an anderer Stelle heißt es:

System und Mensch sind zweierlei, und jeder wird in seine Zeit gestellt. Ich gehöre zu einer Mittlergeneration. Der Krieg hat uns noch elterlich geprägt. Die DDR umgreift einen erheblichen Teil unserer Biographie. Als die Mauer fiel, waren wir noch jung genug, um bei vollen Kräften in die neue Zeit zu gehen. Aber alle unsere Zeiten machen uns aus und erläutern einander. (Dieckmann 2009, S. 76)

Aus größerem Abstand und mit einem geringen DDR-Anteil in der Biographie liest sich das frappierend anders. Der Ost-West-Gegensatz ist, wenn es um die verschiedenen Mentalitäten in deutschen Landen geht, offenbar nicht nur für Claudia Rusch (Jahrgang 1971) eine überholte Kategorisierung. Sie berichtet:

Ich erinnere mich, wie ich im Radio ein Interview mit der Gruppe „Wir sind Helden“ hörte, die erklären sollte, ob es einen Unterschied zwischen Ost- und Westpublikum gäbe. Ich mag diese Frage, die mir ebenfalls mit Penetranz gestellt wird, überhaupt nicht. Sie hinterlässt bei mir oft den Eindruck, dass es gar nicht wirklich um eine Antwort geht, sondern vielmehr um die Bestätigung, dass die anderen anders sind. Dass die arroganten, dummdreisten Wessis keine Ahnung von der DDR haben. Dass im Osten alle behäbig und rosarot ihrer verklärenden Erinnerung nachhängen. Dass das gegenseitige Misstrauen am Ende eben doch berechtigt ist. Weil wir nun mal verschieden sind. Für immer und ewig.

„Nein, eher zwischen Nord und Süd“, hörte ich mich am Steuer automatisch halblaut antworten. „Nein, eher zwischen Nord und Süd“, schallte es echogleich aus dem Äther. (Rusch 2009, 185-186)

Die Mitglieder der hier zitierten (übrigens westdeutschen) Pop-Gruppe sind zwischen 1974 und 1976 geboren. Es scheint, dass - was auch intuitiv plausibel ist (auch wenn wir dafür in den Daten unserer Umfrage keine klare Evidenz finden) - wir es hier vor allem mit einer Generationenfrage zu tun haben. ${ }^{24}$ Der größer werdende zeitliche Abstand zu den erlebten Realitäten von Mauer, von staatlicher Teilung führt zumindest bei Teilen der jüngeren Generationen zu einem gewissen Überdruss an der Differenzdebatte und erlaubt einen stärker regionalisierenden und stark gegenwartsbezogenen Blick auf die Nation.

\section{Literatur}

Bauer, Dirk (1993): Das sprachliche Ost-West-Problem. Untersuchungen zur Sprache und Sprachwissenschaft in Deutschland seit 1945. Frankfurt/Main.

Dieckmann, Christoph (2009): Mich wundert, daß ich fröhlich bin. Eine Deutschlandreise. Berlin.

Eichinger, Ludwig M. et al. (2009): Aktuelle Spracheinstellungen in Deutschland. Erste Ergebnisse einer bundesweiten Repräsentativumfrage. Mannheim.

Gärtig, Anne-Kathrin/Rothe, Astrid (2009): Über Liebe zum Deutschen, Sympathie für Dialekte und Sorge um Sprachentwicklung. Was die Menschen in Deutschland über Sprache denken. In: Sprachreport 3/2009, S. 2-11.

Hellmann, Manfred W. (1998): „Durch die gemeinsame Sprache getrennt“ - Zu Sprache und Kommunikation in Deutschland seit der Wende 1989/90. In: Das Wort - Germanistisches Jahrbuch 1998, S. 51-69. Jetzt in: Herberg (Hg.) (2008), S. 423-441.

Hellmann, Manfred W. (2000): Divergenz und Konvergenz. Sprachlich-kommunikative Folgen der staatlichen Trennung und Vereinigung Deutschlands. Ein Überblick. In: Eichhoff-Cyrus, Karin M./Hoberg, Rudolf (Hg.): Die deutsche Sprache zur Jahrtausendwende. Sprachkultur oder Sprachverfall?. Mannheim. S. 247-275. (= Thema Deutsch 1). Jetzt in: Herberg (Hg.) (2008), S. 483-516.

Hellmann, Manfred W. (2001): Das Bild von der ,Sprache der DDR in der alten Bundesrepublik oder: Haben sie so gesprochen? Rückblicke auf 50 Jahre westdeutsche Attitüden. In: Antos, Gerd/Fix, Ulla/ Kühn, Ingrid (Hg.): Deutsche Sprach- und Kommunikationserfahrungen zehn Jahre nach der „Wende“. Frankfurt/Main. S. 57-79. (= Wittenberger Beiträge zur deutschen Sprache und Kultur 2). Jetzt in: Herberg (Hg.) (2008), S. 517-543.

24 Vgl. auch Hellmann (in diesem Band, S. 229). 
Hellmann, Manfred W. (2003): Forschung zu Sprache und Kommunikation in Deutschland Ost und West Was bleibt noch zu tun? Ein Überblick. In: Wengeler, Martin (Hg.): Deutsche Sprachgeschichte nach 1945. Diskurs- und kulturgeschichtliche Perspektiven. Beiträge zu einer Tagung anlässlich der Emeritierung Georg Stötzels. Hildesheim. S. 364-392.

Hellmann, Manfred W. (2004): Thema erledigt - oder doch noch nicht? Was bleibt zu tun bei der Erforschung des DDR-Sprachgebrauchs? In: Reiher, Ruth/Baumann, Antje (Hg.): Vorwärts und nichts vergessen. Sprache in der DDR - was war, was ist, was bleibt. Berlin. S. 17-26. Jetzt in: Herberg (Hg.) (2008), S. 545-553.

Herberg, Dieter (Hg.) (2008): Manfred W. Hellmann: Das einigende Band? Beiträge zum sprachlichen OstWest-Problem im geteilten und im wiedervereinigten Deutschland. Herausgegeben von Dieter Herberg. Tübingen. (= Studien zur deutschen Sprache Bd. 43).

Hoberg, Rudolf/Eichhoff-Cyrus, Karin M./Schulz, Rüdiger (Hg.) (2008): Wie denken die Deutschen über ihre Muttersprache und über Fremdsprachen? Wiesbaden.

Holly, Werner/Habscheid, Stephan (1997): Vorwort. In: DS 25.2, S. 97.

Identity Foundation (2009): Deutsch-Sein - Ein neuer Stolz auf die Nation im Einklang mit dem Herzen. Die Identität der Deutschen. Eine repräsentative Studie im Auftrag der Düsseldorf Identity Foundation.

Kreutz, Heinz J. (2002): Sprachliche Wiedervereinigung Ost-West. Eine pragmalinguistische Untersuchung zu Erscheinungen kommunikativer Unsicherheit bei jungen Ostbürgern. Mannheim. (= amades 1/02).

Osgood, Charles E./Suci, George J./Tannenbaum, Percy H. (1957): The measurement of meaning. Oxford.

Regener, Irena (2000): Selbstidentifikation via Varietätengebrauch. Sprachverhalten und Spracheinstellungen in der Berliner Sprachgemeinschaft der 90er Jahre. In: Linguistik online 7, 3.

Rusch, Claudia (2009): Aufbau Ost. Unterwegs zwischen Zinnowitz und Zwickau. Frankfurt/Main.

Schönfeld, Helmut (1996): Berlinisch in der zusammenwachsenden Stadt Berlin. In: Zeitschrift für Germanistik N. F. 6, S. 144-159.

Schrodt, Richard (1995): Warum geht die deutsche Sprache immer wieder unter? Die Problematik der Werthaltungen im Deutschen. Wien.

Shaver, Philipp/Schwartz, Judith/Kirson, Donald/O'Connor, Cary (1987): Emotion knowledge: Further exploration of a prototype approach. In: Journal of Personality and Social Psychology, 52, S. 1061-1086.

Spitzmüller, Jürgen (2008): „Sind wir noch Deutsche?“ Der deutsch-englische Sprachkontakt als Thema des öffentlichen Diskurses in der Gegenwart. In: Eichinger, Ludwig M./Plewnia, Albrecht (Hg.): Das Deutsche und seine Nachbarn. Über Identitäten und Mehrsprachigkeit. Tübingen. S. 63-82. (= Studien zur deutschen Sprache 46).

Stevenson, Patrick (2002): Language and German Disunity. A Sociolinguistic History of East and West in Germany, 1945-2000. Oxford.

Stickel, Gerhard (2006) Ost- und westdeutsche Spracheinstellungen. In: Riutort, Macià/Jané, Jordi (Hg.): Der ungeteilte Himmel. Visions de la reunificació alemanya quinze anys després. Tarragona. S. 685-700. (= Forum 12).

Stickel, Gerhard/Volz, Norbert (1999): Meinungen und Einstellungen zur deutschen Sprache. Ergebnisse einer bundesweiten Repräsentativerhebung. Mannheim. (= amades 2/99).

Zahn, Christopher/Hopper, Robert (1985): Measuring language attitudes: the speech evaluation instrument. In: Journal of Language and Social Psychology, 4 (2), S. 113-123.

Dr. Albrecht Plewnia

Astrid Rothe

Institut für Deutsche Sprache

Postfach 101621

D-68016 Mannheim

E-Mail: plewnia@ids-mannheim.de

E-Mail: rothe@ids-mannheim.de 